\title{
Kapitel 6. \\ Nonnos und die Rhetorik als poetische Technik
}

\author{
Ampelo, la tua fine prova lo splendore del tuo corpo. \\ Anche morto, non hai perso il tuo colore rosato. Nessuno altro dio, \\ non certo Atena col suo sobrio ulivo, e neppure Demetra \\ col suo pane corroborante, avevano in loro potere qualcosa \\ che si avvicinasse a quel liquore. Era appunto \\ ciò che mancava alla vita, che la vita aspettava: l'ebbrezza.
}

Roberto Calasso ${ }^{1}$

\subsection{Zum Einfluss der Rhetorik in der Spätantike}

Seit Beginn der griechischen Literatur spielt die rhetorische Ausgestaltung literarischer Werke, auch ohne theoretisches Fundament, eine wichtige Rolle: Schon Homer gestaltet seine Figurenreden nach rhetorischen Grundprinzipien und bietet umfangreiche Ekphrasen wie etwa die Schildbeschreibung, die fortan zum epischen Standardrepertoire gezählt werden. ${ }^{2}$ Mit der Entwicklung und Etablierung der rhetorischen Theorie und Praxis im Zuge der Sophistik werden die Regeln der Rede- und Argumentationskunst kanonisiert und als standardisiertes Allgemeingut in die griechische Literatur aufgenommen, um, zum Gegenstand des antiken Schulunterrichts geworden, die über Jahrhunderte tradierten erzieherischen Konventionen zu pflegen und bis in die Spätantike und darüber hinaus auch in Byzanz die Basis für jegliche Form höherer Bildung zu legen. ${ }^{3}$ Die Präsenz der Rhetorik in der Spätantike ist Mittel und Ausdruck des gesellschaftlichen Selbstverständnisses, einer Griechisch sprechenden sozialen Elite des Ostens, welche sich über (rhetorische) Bildung identifiziert und definiert: „Under the Roman Empire, the governing classes maintained their identity partly through their participation in a highly conservative education system which stressed facility in language from grammar to sophisticated rhetorical composition, and in which the close study of specific literary texts was central. “4 Dieser literarische Konservativismus fördert in der Spätantike die Herausbildung einer „culture frozen in the past with little attention devoted to contemporary authors and issues“. ${ }^{5} \mathrm{Da}$ die Ausbildung der Oberschicht, welche auf der Grundlage der literarischen Traditionen

1 Calasso (1988) 51.

2 Vgl. Kennedy (1999) 7 -11. - Homer diente nicht nur als Referenzautor für das Erlernen von Lesen und Schreiben in der Elementarschule, sondern nahm auch einen besonderen Platz im Kanon der Schulautoren in der Rhetorikausbildung des griechischen Ostens ein, vgl. Cribiore (2001) 194-197. 3 Zum spätantiken Schul- und Bildungswesen vgl. Jones A. H. M. (1986) Bd. 2, 986 - 1012; Bowersock u. a. (1999) $421-423$.

4 Scourfield (2007) 5.

5 Cribiore (2001) 247. 
der vergangenen Jahrhunderte fußte, der Schlüssel zur Erlangung einer Stelle in der Administration des römischen Reiches darstellte, ${ }^{6}$ kommt der Rhetorik eine herausragende gesellschaftliche Funktion zu. Angehörige der sozialen Elite unterziehen sich in einem der regionalen oder überregionalen Bildungszentren der gleichen Ausbildung, ungeachtet ihrer Konfessionszugehörigkeit. Heiden wie Christen verfügen über den gleichen Bildungsstand, Persönlichkeiten der christlichen Kirche wie Basileios von Kaisareia oder Augustinus erhalten eine Ausbildung, die vergleichbar mit der des heidnischen Rhetors Libanios ist. Die Kirchenväter des lateinischen Westens und des griechischen Ostens legen mit ihren Schriften Zeugnis vom Einfluss der literarischen und kulturellen Errungenschaften der heidnischen Kultur(en) auf die neue Religion $\mathrm{ab.}^{7}$

Die Dionysiaka und somit auch die Ampelos-Episode sind Ergebnis dieser höchst konservativ ausgerichteten Bildungsgesellschaft, für die profunde Kenntnisse in der Rhetorik ein wesentlicher Teil ihrer Selbstidentifikation darstellten. Ein Überblick über die Forschungslage zur Rhetorik in den Dionysiaka (Kapitel 6.2) bildet die Grundlage für die anschließende Analyse der Ampelos-Episode und ihrer rhetorischen Darstellungsprinzipien (Kapitel 6.3, 6.4 und 6.5): Um Nonnos’ poetische Qualität und Innovationsfreude auf dem Gebiet der rhetorischen Techniken zu veranschaulichen, wird die Umsetzung der rhetorischen Genera Synkrisis, Enkomion und Ekphrasis in den Büchern 10-12 beleuchtet. Ziel dieses Kapitels ist es zudem, Hinweise auf die Konzeption der Dionysiaka insgesamt zu erhalten und die Nutzung rhetorischer Prinzipien in den Kontext der spätantiken Gesellschaft des östlichen Mittelmeerraums einzuordnen. Außerdem soll der Blick auf die biographisch-prosopographischen Erzähllinien, für die der Dichter beim Genus Enkomion Anleihe nimmt, das spätantike Literaturschaffen insgesamt charakterisieren. ${ }^{8}$ Dabei sollen die Musterbilder der rhetorischen Genera in den Progymnasmata an keiner Stelle im Sinne direkter Quellentexte für Nonnos, sondern vielmehr als Inspirationsquelle für seine eigene literarische Schaffenskraft verstanden werden.

Die städtischen Zentren des östlichen Mittelmeerraums, in welchen in der Spätantike höhere rhetorische Bildung gelehrt wird, Athen, Alexandria, Antiochia, Aphrodisias, Gaza und Konstantinopel, bringen die wichtigsten Repräsentanten spätantiker Literatur hervor. ${ }^{9}$ Mit Alexandria verfügt auch Ägypten über ein überregional bedeutendes Bildungszentrum, in dem heidnische und christliche Literaten,

6 Vgl. Marrou (1948) 120 - 122; Bowman (1996) 140; Cribiore (2001) 249; Liebeschuetz (2001) 223 f.; Cribiore (2007) $197-199$.

7 Vgl. Liebeschuetz (1996) 75: „In the late Roman world as under the earlier Empire it was literary education more than origin that distinguished the gentleman, the person thought worthy of posts of distinction in city or empire. It was the religion of rhetoric which united the ruling groups of the empire“; vgl. auch Cameron Averil (2006) 19; zum Verhältnis der Christen zur heidnischen Bildung allgemein siehe Marrou (1948) 132 -147; Gemeinhardt (2007).

8 Zur Bildhaftigkeit in den Dionysiaka siehe Roberts (1989) 56; Hernández de la Fuente (2008) 36. 9 Vgl. Kennedy (1983) 149-179; Cribiore (2007) 30, 47-82; Cribiore (2007a) 54-57. 
Verwaltungsbeamte und Kirchenmänner eine solide rhetorische Ausbildung erhalten. ${ }^{10}$ Neben der ägyptischen Hauptstadt stellen auch die weiter nilaufwärts gelegenen Städte Aphrodito, Antinoopolis und Panopolis wesentliche regionale Zentren antiker Bildung dar, wobei für Panopolis auf die Existenz einer Bibliothek geschlossen werden kann, die über griechische, lateinische und koptische Texte verfügte, ebenso auf die einer Rhetorenschule, was die Herkunft mehrerer literarischer Persönlichkeiten im 5. und 6. Jh. n. Chr. aus dieser Stadt erklärt. ${ }^{11}$

Worauf stützen nun die Rhetorenschulen der Spätantike ihren Unterricht? Welche Fähigkeiten und Fertigkeiten werden dem Zielpublikum vermittelt? Der Anspruch eines jeden Studenten der Rhetorik in der Spätantike ist es, rhetorische Mittel und Fertigkeiten in der beruflichen Praxis anwenden zu können, Lehrziele, die nicht nur den Erwerb von traditionellen, heidnischen Inhalten umfassen, sondern auch den Erwerb des gesellschaftlichen Codes dieser Elite mit einschließen. Am Beginn des Rhetorikstudiums steht die Einübung rhetorischer Muster und unterschiedlicher Redetypen unter strenger Einhaltung festgelegter und vorgegebener Kompositionsprinzipien auf der Grundlage schematisierter Übungen, der sog. Progymnasmata. ${ }^{12}$ Spätestens ab dem 1. Jh. n. Chr. werden Studenten in einzelnen, klar definierten Trainingseinheiten mit Thema, Form und Aufbau standardisierter rhetorischer Gattungen vertraut gemacht: „They learned a highly structured, approved way of narrating, amplifying, describing, praising, criticizing, comparing, proving, and refuting something. "13 Die einzelnen rhetorischen Genera und deren Aufbauprinzipien sind in den Handbüchern zur rhetorischen Praxis der kaiserzeitlichen Autoren Theon, Ps.Hermogenes, Aphthonios und Nikolaos tradiert, Muster-Progymnasmata sind außerdem vom einflussreichen Rhetoriklehrer Libanios aus Antiochia erhalten. ${ }^{14} \mathrm{Im} 4$. Jh. n. Chr., der Blütezeit der rhetorischen Prosa, gehören Persönlichkeiten wie Himerios aus Athen, Libanios aus Antiochia oder Themistios aus Konstantinopel zu den Angesehensten ihrer Zunft, im 5. und 6. Jh. n. Chr. setzen die Vertreter der sog. Schule von Gaza, darunter Chorikios, Prokopios und Aeneas von Gaza, die lebendige rhetorische Tradition fort. ${ }^{15}$

10 Vgl. Cameron Averil (2012) 130-134.

11 Außer Nonnos sind dies z. B. der Dichter und Philosoph Kyros von Panopolis und der Alchemist Zosimos von Panopolis. Zu Ägypten als Zentrum der griechischen Literatur und des spätantiken Philhellenismus siehe Bagnall (1993) 99-105, 251-260; Cribiore (2007a) 58-62; zum Dichter Dioskoros von Aphrodito, der sich von der Sprache des Nonnos inspirieren ließ, siehe Fournet (1999); Dijkstra (2003); Fournet (2003a); MacCoull (2003); Capra (2012).

12 Vgl.Viljamaa (1968) 13 f.; Kennedy (1983) 25, 53 - 69; Kennedy (1984) 22 f.; Kennedy (1994) 202 228; Swain (1996) 28, 90f.; Kennedy (1999) 26-28; Cribiore (2001) 221-244; Miguélez Cavero (2008) 264f.; Webb (2009) 14, $39-48$.

13 Kennedy (1999) 27.

14 Vgl. Cribiore (2007) 144f.; Gibson (2008).

15 Zur Schule von Gaza siehe Downey (1958); Downey (1969) 95; Kennedy (1983) 169-176; Kennedy (1994) 242 - 255, 271; Ciccolella (2000) 118-126; Ashkenazi (2004). 
Die rhetorischen Paradeigmata dienen nicht nur dem ausgebildeten Rhetor, sondern allen Literaturschaffenden zur Intensivierung und Steigerung der Aussage ihrer Texte ${ }^{16}$ und finden sich daher nicht nur in Werken rhetorischer Prosa, sondern in sämtlichen literarischen Gattungen. George Kennedy spricht in diesem Zusammenhang von einer ,tendency of the teaching of rhetoric itself to slip from exposition of an art of public address to techniques of literary composition“. ${ }^{17}$ Die Rhetorik wird als geschlossenes literarisches Genus aufgebrochen und greift auf andere Gattungen über, ihr Einfluss, insbesondere ihrer epideiktischen Formen, gilt auch für die spätantike Dichtung, die sich im 5. und 6. Jh. n. Chr. großer Popularität erfreut und die der noch im 4. Jh. n. Chr. favorisierten rhetorischen Prosa allmählich den Rang abläuft. ${ }^{18}$ Aus der Tatsache, dass beide, Rhetoren und Dichter, dieselbe Schul- und Studienausbildung durchlaufen, ergibt sich die Bedeutung rhetorischer Gesetzmäßigkeiten für alle literarischen Gattungen: Rhetorik und Dichtung folgen oftmals denselben rhythmischen, stilistischen und kompositorischen Regeln, ${ }^{19}$ sodass insbesondere die spätantike und frühbyzantinische Kleindichtung sich rhetorischer Stilmittel und Ausdrucksformen bedient. Für Dichter wie Johannes Geometres sind Komposita, Asyndeta, Allegorien, Sprachbilder, der Einsatz von Partizipien und dergleichen die Grundlagen ihres dichterischen Schaffens; Standardthemen wie Frühling und Vegetation oder rhetorische Mittel wie Ekphrasis, Ethopoiie, Epithalamium und Enkomion begegnen allenthalben, ${ }^{20}$ sodass von einer regelrechten „retorizzazione“ ${ }^{\text {“21 }}$ der spätantiken Dichtung gesprochen werden muss. Umgekehrt bedienen sich heidnische Rhetoren auch poetischer Darstellungsmittel, etwa mythischer exempla, wie sie für das Epos konstitutiv sind, ${ }^{22}$ und auch ihre christlichen Pendants operieren mit rhetorischen Gestaltungsprinzipien, etwa im Genus der Bibelepik, das im Griechischen insbesondere durch die Paraphrase des Nonnos greifbar wird. ${ }^{23}$

16 Vgl. Kennedy (1999) 27: „Progymnasmata are important for the study of Greek and Latin literature of the Hellenistic and Roman periods in that the exercises often supplied writers with structural units in their works and with techniques of amplification." - Zum Verhältnis von Dichtung und Rhetorik allgemein siehe Webb (1997a).

17 Kennedy (1983) $17 \mathrm{f}$.

18 Vgl. Viljamaa (1968) 10-36.

19 Vgl. Kennedy (1983) 28; Thomas u. Webb (1994) 20; Kennedy (1999) $135 \mathrm{f}$.

20 Vgl. Ciccolella (2000) XXXIV, LV-LXI. - Auch in der byzantinischen Poesie finden sich Beispiele für die Verarbeitung dieser Gattungen, z. B. in den Ekphrasen und Enkomien des Johannes Geometres im 10. Jh.; zu Johannes Geometres vgl. Littlewood (1972); van Opstall (2008).

21 Agosti (2005) 35.

22 Vgl. Cribiore (2007) $161 \mathrm{f}$.

23 Zur literarischen Verfahrensweise der Bibelepik vgl. ausführlich Roberts (1985) 5-36; für die Übernahme rhetorischer Techniken in Nonnos' Paraphrase siehe Golega (1930) 92 - 98. 


\subsection{Rhetorik in den Dionysiaka - ein Forschungsüberblick}

Die Anwendung eines ganz bestimmten rhetorischen Elements in der Ampelos-Episode hat als Erster Georg Wild herausgearbeitet: In einem Überblick über die Gleichnisse bei Nonnos nennt er auch die für Ampelos vorgebrachten mythischen Vergleichsfiguren wie etwa Narkissos, Hylas oder Ganymed. ${ }^{24}$ Während Wild den Rahmen der epischen Gleichnisse nicht verlässt und nirgendwo explizit von der rhetorischen Kategorie der Synkrisis spricht, stellt die Forschung zu Beginn des 20. Jhs. erstmals die Verbindung zwischen Nonnos und verschiedenen rhetorischen Techniken her: Viktor Stegemann liefert zusätzlich zu seiner kosmologischen Interpretation des Epos auch einen tabellarischen Überblick über den Aufbau der Dionysiaka und bringt

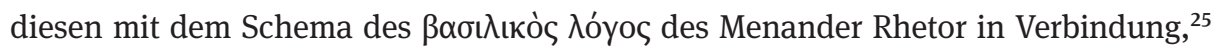
wonach wie für Alexander den Großen auch für Dionysos ein mythischer ßíos zu rekonstruieren sei. Auch Hans Gerstinger greift die Enkomion-Theorie auf, stellt diese aber auf eine breitere Basis, indem er nicht ausschließlich Menander Rhetor, sondern das Genus der Progymnasmata als solches der Konzeption der Dionysiaka zugrunde legt. ${ }^{26}$ Der enkomiastische Zug äußert sich demzufolge in den großen Kompositionslinien des Epos, in denen der Dichter chronologisch von der Geburt bis zur Apotheose des Dionysos verfährt und es sich zum Ziel macht, Dionysos' Entwicklung und Werdegang bis zur Aufnahme in den Olymp darzustellen. Das Enkomion sieht Gerstinger als nur eines von mehreren kompositorischen Konzepten der Dionysiaka, eine Ansicht, der sich in der Folge auch Helmut Haidacher, Gennaro D’Ippolito und Barbara AbelWilmanns anschließen. ${ }^{27}$ Im Rahmen seines Quellenstudiums zu den Dionysiaka geht Helmut Haidacher auch auf den Einfluss der Rhetorik ein: Nonnos, der Dionysos' Geschichte nach dem Schema des rhetorischen Enkomions erzähle, bediene sich innerhalb dieses narrativen Rahmens vor allem ekphrastischer Elemente und füge ebenfalls rhetorisch durchkomponierte direkte Reden ein. D’Ippolito arbeitet zudem heraus, dass das Enkomion neben anderen Gattungen wie etwa dem Epyllion für den Aufbau des Epos bestimmend sei. Einen Schwenk zurück zu Stegemann vollzieht

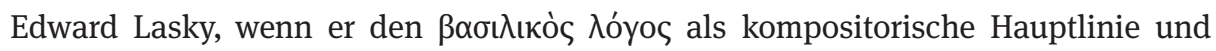
Schlüssel zum Verständnis der Dionysiaka wertet: ${ }^{28}$ Zunächst sei die gesamte AmpelosEpisode im Rahmen des Enkomions auf Dionysos als Jugendgeschichte des Gottes zu

24 Vgl. Wild (1885-1886) 13, 31, 33, 41.

25 Stegemann (1930) 209-230; vgl. auch Bogner (1934) 327. - Gegen die Überbetonung der Enkomion-Theorie durch Stegemann sprechen sich seine Zeitgenossen Paul Collart und Rudolf Keydell aus, Collart (1930) 275f.; Keydell (1936) $909 \mathrm{f}$.

26 Vgl. Gerstinger (1943-1947) 78-81.

27 Vgl. Haidacher (1949) 3, 5, 87 - 92; D’Ippolito (1964) 53, 91-93; Abel-Wilmanns (1977) 51.

28 Lasky (1978) 360 sieht das Schema des Enkomions als „unifying influence of the poem“. Zur Deutung der Dionysiaka als enkomiastisches Epos siehe auch Miguélez Cavero (2008) 355-370 und Trypanis (1981) 394, der das Werk als „a grand epic encomium“ bezeichnet. 
verstehen: ${ }^{29}$ „[...] we can see that the Ampelus episode is actually a dramatization and an extension of that portion of the encomium which is usually reserved for the

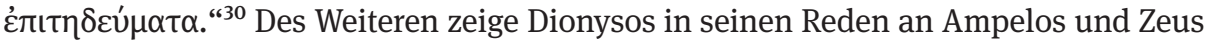
(Nonn. D. 10,196-216, 292-320) seine persuasiven Qualitäten als Rhetor: ${ }^{31}$ „Using persuasion instead of force in his dalliance with the young satyr, Dionysus has made a choice which confers upon him the unique weapon of wine and which will alter the course of his mature deeds. “32

Die allzu starke Gewichtung des Enkomions als alleiniger kompositorischer Kraft, wie sie in der älteren Nonnos-Forschung vertreten wurde, wird in aktuellen Studien, etwa von Robert Shorrock, David Hernández de la Fuente und Anna Maria Lasek, insofern wieder relativiert, als das Enkomion als einer von vielen Mosaiksteinen zum tieferen Verständnis der Dionysiaka gilt. ${ }^{33}$ Insbesondere die kompositorischen Hauptlinien der ersten Bücher werden mittels des Enkomion-Schemas nachvollziehbar: In den Büchern 1-5 steht mit Kadmos, Harmonia und deren Nachkommen Dionysos' Familie im Zentrum, Buch 6 bringt mit Zagreus ebenfalls einen Vorfahren des Gottes, die Bücher 7-12 schildern Geburt, Kindheit und Jugend des künftigen Weingottes. ${ }^{34}$ Auch für die übrigen Bücher lassen sich, wenngleich in geringerer Dichte, enkomiastische Züge festmachen, so etwa in den Indien-Kämpfen, die Dionysos' Leistungen im Krieg zeigen (Nonn. D. 13-40), und in der friedlichen Verbreitung des Weines in den Büchern 41-48.

Eine überzeugende Darstellung des Einflusses der Rhetorik auf die Dionysiaka gibt Laura Miguélez Cavero, die einige ausgewählte Reden der Dionysiaka den entsprechenden Progymnasmata zuordnet und festhält, dass für Nonnos insbesondere deliberative und epideiktische Formen relevant seien. ${ }^{35}$ Zudem stellt sie einen Bezug der Reden zur Erzähllinie der Dionysiaka fest, indem sie die Reden nicht isoliert vom Kontext des Erzählverlaufes, sondern stets auf diesen bezogen wissen will. ${ }^{36}$ Miguélez Cavero bespricht insgesamt fünf Gattungen der Progymnasmata - Diegesis (narratio), Ekphrasis, Paraphrase, Ethopoiie und Enkomion - und zeigt anhand ausgewählter Beispiele aus Triphiodor, Musaios, Kolluthos und Nonnos ihre dichterische Umsetzung. ${ }^{37}$ Für die Ampelos-Episode konstatiert Miguélez Cavero, dass diese innerhalb des

29 Vgl. Lasky (1978) 359, 366; Miguélez Cavero (2008) 358 weist ähnlich wie Lasky auf die Funktion der Ampelos-Episode als Jugendgeschichte innerhalb des chronologisch ablaufenden Enkomions auf Dionysos hin.

30 Lasky (1978) 370.

31 Vgl. Lasky (1978) $367 \mathrm{f}$.

32 Lasky (1978) 370.

33 Vgl. Shorrock (2001) 15f.; Hernández de la Fuente (2008) 31, 48; Lasek (2009) 134.

34 Vgl. Vian (1976) XXIII; Hernández de la Fuente (2008) 65.

35 Vgl. Miguélez Cavero (2008) 265; zur Definition der epideiktischen Rede als Festrede auf eine Person oder Personengruppe vgl. Kennedy (1983) 24; zum Enkomion allgemein siehe auch Miguélez Cavero (2008) 355-366.

36 Vgl. Miguélez Cavero (2008) $268 \mathrm{f}$.

37 Vgl. Miguélez Cavero (2008) 264-370. 
Enkomion-Schemas einen Abschluss der Jugenderzählung des Dionysos bilde und dass der zukünftige Gott mit seiner ersten Liebe konfrontiert und mit seinem wichtigsten Attribut, dem Weinstock, ausgestattet werde; ${ }^{38}$ die Ampelos-Episode sei in ihrer Gesamtkonzeption Teil der rhetorischen Standardübung Enkomion. Auf die rhetorischen Elemente, die in der Episode selbst zu finden sind, nimmt Miguélez Cavero nur am Rande Bezug und zeigt mit der Analyse der Ate-Rede (Nonn. D. 11,118-154) exemplarisch den Einfluss des rhetorischen Genus der Diegesis auf die mythisch-narrativen Passagen. ${ }^{39}$ Auch Gianfranco Agosti und Domenico Accorinti heben die Bedeutung ekphrastischer Partien hervor, durch die sich Nonnos vom klassischhomerischen Epos absetzt. ${ }^{40}$ Die Dominanz des Deskriptiven wird zum charakteristischen Stilmerkmal des spätantiken Epos erkoren, das gänzlich anderen narrativen Gesetzmäßigkeiten gehorcht als das homerische Epos und sich in vielen einzelnen Aspekten eng an hellenistischen Traditionen orientiert. ${ }^{41}$

Die angeführten Arbeiten bieten entweder eine Auswahl einzelner Aspekte der Rhetorik in der Ampelos-Episode oder liefern oft lediglich generalisierende Feststellungen für das ganze Epos. Ziel der folgenden Ausführungen ist die Darstellung und Analyse der rhetorischen Elemente der Ampelos-Episode in ihrer Gesamtheit, indem insbesondere der Frage nachgegangen wird, auf welche Weise Nonnos die rhetorischen Gattungen Synkrisis, Enkomion und Ekphrasis für seine Ampelos-Episode fruchtbar macht und mit einer festen narrativen Funktion versieht. Aufgezeigt wird die erzählerische Dynamik der rhetorischen Ausdrucksformen und ihre Einpassung in den Erzählverlauf der Episode. Die Ergebnisse der Untersuchung werden in einen größeren kompositorischen Kontext gesetzt und sollen zu einem besseren Verständnis der Komposition der Dionysiaka insgesamt beitragen.

38 Vgl. Miguélez Cavero (2008) 358.

39 Vgl. Miguélez Cavero (2008) 281f.; nicht besprochen werden von Miguélez Cavero die übrigen zahlreichen Figurenreden der Ampelos-Episode (z. B. Nonn. D. 10,196-216; 11,7-42, 74-80; 12,207 - 289). - Miguélez Cavero (2008) 170 - 172 verweist außerdem auf den Einfluss anderer Genera auf die Ampelos-Episode wie z. B. der Epigrammatik; von den insgesamt sechs Epitaphien in den Dionysiaka ist mit dem Grabgedicht auf Karpos (Nonn. D. 11,475 f.) auch eines in der Ampelos-Episode zu finden.

40 Vgl. Agosti (1995); Agosti (2008) 18; Accorinti (2009) 93-95; Agosti (2009) 110-113; außerdem Braden (1978) $72 \mathrm{f}$.

41 So etwa Miguélez Cavero (2008) 268: „The presence of narrative in late antique epic is very restricted, due to its progressive slide towards description [...].“ - Die Literatur zur Ekphrasis und zum Einfluss des Deskriptiven in Spätantike und Mittelalter ist umfangreich, siehe etwa Byre (1976); Maguire (1981) 22f.; Hebert (1983); Garzya (1984) 29-33; Roberts (1989) 38-44; Manakidou (1993); Goldhill u. Osborne (1994); Graf (1995); Boeder (1996), bes. 28 - 45; Andersen (2001); Elsner (2002a); Gigli Piccardi (2003) 24 - 26; Wandhoff (2003) 1 - 11; Arnulf (2004); Hose (2004) 10 f.; Green (2006) 55 f.; Ratkowitsch (2006); Labarre (2009); Vavřínek u. a. (2011). 


\subsection{Die Synkrisis}

Der ansonsten in der mythisch-literarischen Tradition kaum greifbare Satyr Ampelos erhält seine Charakterzeichnung zu einem erheblichen Teil aus dem Vergleich mit anderen prominenteren Figuren des antiken Mythos. ${ }^{42}$ Hierbei bietet Nonnos regelrechte Mythenkataloge auf, in denen jugendliche Göttergeliebte Ampelos als Spiegelbild dienen. ${ }^{43}$ Aussehen, Eigenschaften und Schicksal des Knaben sind von Nonnos jedoch nicht bloß aus vorhandenen Traditionen geschöpft, der Satyr und Liebling des Dionysos wird vielmehr in den unmittelbaren erzählerischen Kontext eingebunden, die Etablierung von Wein und dionysischem Kult ist das Ziel der Episode.

Das übermäßige Aufgebot an Vergleichsfiguren für Ampelos ist auffällig, keine andere Figur in den Dionysiaka wird so sehr über andere Figuren definiert, und dennoch ist eine derartige literarische Technik der Profilierung durch Vergleich keineswegs neu, ist doch die Synkrisis ein geschätztes rhetorisches Genus. Anleitungen zur Abfassung einer Synkrisis finden sich in den kaiserzeitlichen Progymnasmata, etwa des Aphthonios (Aphth. Prog. 10,1): ${ }^{44}$

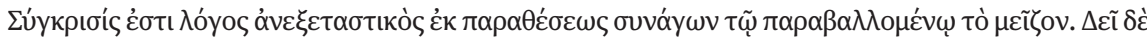

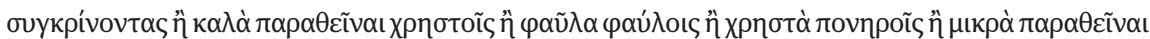

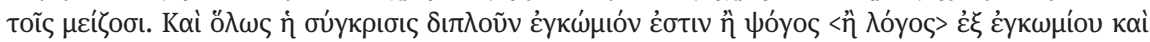

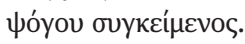

Die Synkrisis ist eine Rede, die in Form einer Gegenüberstellung etwas Großes in Vergrößerung mit einem Vergleichsgegenstand zusammenführt. Man muss bei der Gegenüberstellung Gutes mit Nützlichem, Schlechtes mit Schlechtem, Nützliches mit Schlechtem oder Kleines mit Großem vergleichen. Und aufs Ganze gesehen ist die Synkrisis ein doppeltes Enkomion oder ein Psogos, der sich aus Lob und Tadel zusammensetzt.

Aufs Engste mit der Synkrisis sind Lob und Tadel verknüpft, wie Aphthonios festhält, der rhetorische Vergleich ist somit essentieller Bestandteil von Enkomion und Psogos. ${ }^{45}$ Die Praxis der Synkrisis gelangt dort zum Einsatz, wo einer historischen oder

42 Vgl. Kap. 4.

43 Vgl. Ganymed und Pelops in Dionysos' Bittrede an Zeus in Nonn. D. 10,256-263 sowie Hyakinthos und Atymnios in Dionysos' erster Klagerede in Nonn. D. 11,255-263.

44 Text: Patillon (2008) 140f., Übersetzung die Vf.; vgl. auch Nicol. Prog. 59-63 Felten und Theon Prog. 9,1, demzufolge es sich dabei um den Vergleich von verschiedenen Personen, Gegenständen oder Abstrakta mit dem Zweck einer abschließenden Bewertung handelt. - Zur Definition von Synkrisis siehe auch Clark (1957) 198f.; Kennedy (1983) 25; Kennedy (1994) 205; Desbordes (1996) 134; Lausberg (2008) 333-335, 542 f.; Miguélez Cavero (2010) 35- 40.

45 Die Synkrisis kommt auch in Epitaphien zum Einsatz, etwa in der Rede, die Themistios auf seinen verstorbenen Vater hält (Them. Or. 20): Der Vater wird je einer Persönlichkeit aus der athenischen Geschichte (Sokrates) und der Mythologie (Herakles) gegenübergestellt; der Vergleich dient dem Preis und der Huldigung des Vaters und ist zugleich Repräsentation paganer Gelehrsamkeit. Auch Himerios zeigt, dass er die rhetorische Technik der Synkrisis beherrscht: In einer Rede auf den Geburtstag eines Freundes findet sich eine Synkrisis mythischer Figuren (Him. Or. 44,4); siehe auch die zahlreichen 
mythischen Person oder aber auch einem göttlichen Prinzip Fürsprache gewährt werden soll. Auch Nonnos stellt sich in diese Tradition und macht sich die Synkrisis für seine Dionysiaka vielfach zunutze, indem er sie immer dann einsetzt, wenn der Protagonist Dionysos gegenüber anderen Göttern abgesetzt und positiv hervorgehoben oder aber die schicksalshafte Verwandlung des Ampelos in einen Weinstock effektvoll in Szene gesetzt werden soll.

Sinnbilder für die dionysische Wirkkraft, die im Rahmen der Ampelos-Episode zum ersten Mal direkt und unvermittelt in Erscheinung tritt, sind der Weinstock und das daraus gewonnene Getränk, der Wein. Beide präsentiert der Dichter auf der Grundlage einer Reihe von Synkriseis mit anderen göttlichen Pflanzen und Kulturprodukten des Mythos in der Absicht, die dionysische Pflanze als in allen Punkten überlegen zu stilisieren. Den Kern dieser rhetorischen Linie bildet Dionysos' letzte Rede im 12. Buch, wo er Ampelos mit den Geliebten Apolls, die Weinrebe mit anderen Kulturpflanzen sowie sich selbst mit anderen Göttern vergleicht (Nonn. D. 12,207289). ${ }^{46}$ Die übrigen Blumen und Nutzpflanzen werden am Weinstock gemessen und für minderwertig befunden: Lorbeer und Hyazinthe bringen nur ungenießbare Früchte

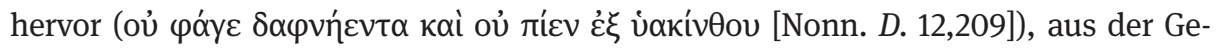

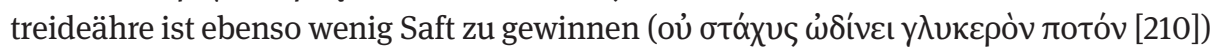

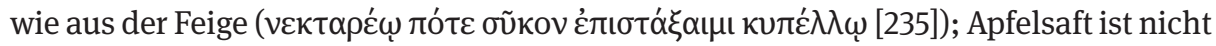
geeignet, mit Wasser vermischt zu werden, und weder Rose noch Narzisse, Anemone, Lilie und Hyazinthe kommen den vielseitigen Qualitäten des Weines auch nur einigermaßen nahe (231-244). ${ }^{47}$ Auf zwei rhetorische Fragen (Nonn. D. 12,224f.) folgt eine katalogartige Aufzählung von als minderwertig klassifizierten Pflanzen, sprachlich wirkungsvoll in Szene gesetzt durch sechsfache Negation (oủ, oủk und oủx [237-239]), wodurch die Weinpflanze als Königin des Pflanzenreichs sämtliche nützlichen und positiven Eigenschaften anderer Gewächse in sich vereint. Um die universelle Gültigkeit der neuen Pflanze zu akzentuieren, bedient sich Nonnos ferner eines Wort-

mythologischen und historischen exempla für den verstorbenen Prokopios in Chor. VIII (= Or. 7) Foerster u. Richtsteig, vgl. auch die Edition in Greco (2010) 57 - 81; siehe außerdem Stat. silv. 3,4, wo Earinus, ein Lieblingsknabe des Kaisers Domitian, mit anderen Schönlingen verglichen wird, vgl. Malamud (1989) 123 f. - Auch christliche Autoren bedienen sich paganer Beredsamkeit und wenden die Synkrisis an: So stellt sich etwa Gregor von Nazianz am Ende von De spiritu sancto die Frage, womit Gott verglichen werden könne (einem Auge, einer Quelle, einem Fluss, der Sonne und ihren Strahlen), um schließlich jegliche Vergleichsmöglichkeit zurückzuweisen und die Einzigartigkeit Gottes herauszu-

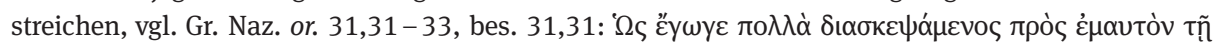

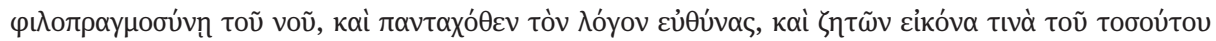

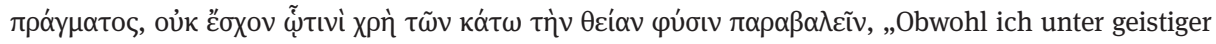
Anstrengung schon vieles für mich sorgfältig geprüft und nach allen Seiten hin logische Schlussfolgerungen gezogen habe, um ein Bild für diese so große Sache zu finden, habe ich nichts unter den irdischen Dingen gefunden, womit man die göttliche Natur vergleichen könnte“, und Gr. Naz. or. 31,33:

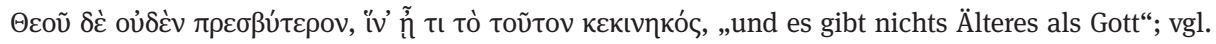
Kennedy (1983) 27.

46 Vgl. Hollis (1994) 48 f.; Vian (1995) 255; Miguélez Cavero (2010) 36.

47 Für den griechischen Text und die deutsche Übersetzung siehe S. 169-172. 


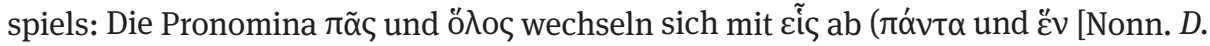

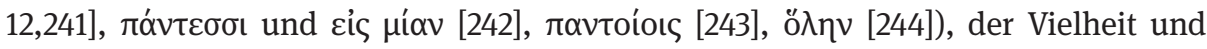
Heterogenität sämtlicher bisher bekannten Pflanzen stehen die in sich geschlossene Einheit und Homogenität der Weinpflanze gegenüber. Der Absolutheitsanspruch der Weinrebe geht mit Ampelos' herausragendem Status einher. Der Dichter spielt mit der Ambiguität der Ampelos-Figur, die zuerst Satyr, dann Pflanze ist, wenn er fünf Possessivpronomina für Ampelos nach seiner Metamorphose aufbietet, als ob dieser noch

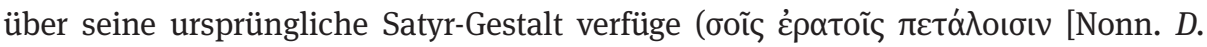

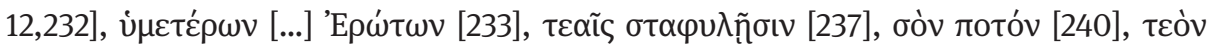
öv $\theta$ os [244]). ${ }^{48}$ In der Fusion von Figur und Pflanze geht Nonnos noch einen Schritt weiter, indem er den in einen Weinstock verwandelten Ampelos als „Spross des

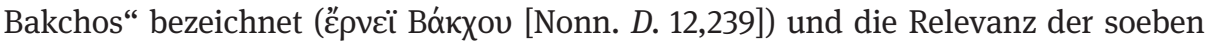
erfolgten Metamorphose für die menschliche Zivilisation durch den prophetischen Grundtenor der Passage hervorkehrt, der durch die Futur- und Optativ-Formen erzeugt

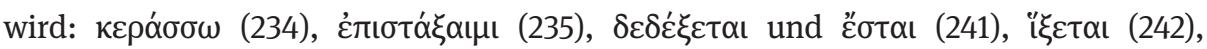

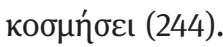

Nonnos wird der Funktion der Synkrisis insofern in vollem Unfang gerecht, als er diese in der Ampelos-Episode in den Dienst des Enkomions stellt..$^{49}$ Die Vergleiche der verschiedenen Kulturpflanzen mit dem Wein haben das Ziel, Dionysos und seine göttliche Allmacht zu würdigen. ${ }^{50}$ Die Synkrisis der Pflanzen bildet den Ausgangspunkt für die Verortung des neuen Gottes in der Welt: So wie der Wein den Gipfel des floralen Panoptikums beschreibt, ist Dionysos über die anderen Götter zu stellen. In diesem Sinne schließt Nonnos in den Versen Nonn. D. 12,245-269 Synkriseis zwischen dem Weingott, Apoll, Ares, Demeter und Athene an, in die er die entsprechenden Pflanzen einflicht.

\subsection{Das Enkomion}

Enkomion und Panegyrik gehören bis in die Spätantike und darüber hinaus zu den beliebtesten rhetorischen Genera, ${ }^{51}$ Enkomiastik ist fester Bestandteil des spätantiken und byzantinischen Kaiserkultes sowie der Verehrung kaiserlicher Honoratioren, zum

48 Vgl. Vian (1995) 255.

49 Men. Rh. 2,372,21 - 25 empfiehlt der rhetorischen Emphase wegen, alle Elemente des $\beta \alpha \sigma ı \lambda ı$ เ̀ 入óyos mit einer Synkrisis zu versehen, vgl. Miguélez Cavero (2010) 35.

50 Dass ein Gott und die ihm zugeschriebene Pflanze Gegenstand einer Synkrisis sein können, wird schon in den Progymnasmata festgehalten: Ps.-Hermogenes bemerkt, dass bei der Synkrisis von Pflanzen sämtliche Vor- und Nachteile, ihre Früchte, die Orte, an denen sie wachsen, und insbesondere

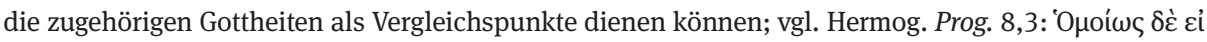

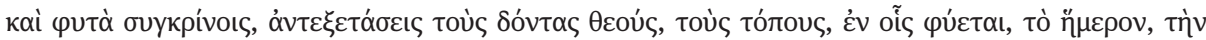

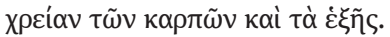

51 Vgl. den Sammelband Whitby (1998) sowie Cameron Alan (2007) 31 und Webb (2009) 135. 
Beispiel in den Dichtungen des Claudius Claudianus. Rhetorische Übungsstücke, wie sie etwa auch in den Progymnasmata des Libanios zu finden sind, ${ }^{52}$ gelangen auch in der spätantiken Dichtung vermehrt zur Anwendung, in der das traditionelle mythische Epos um enkomiastische Elemente erweitert wird. Epische Enkomien oder enkomiastische Epen sind meist nur indirekt oder durch Fragmente bezeugt, ${ }^{53}$ der Überlieferung in den Papyri zufolge genoss die Gattung des Vers-Enkomions in Ägypten jedoch besondere Beliebtheit. ${ }^{54}$ Als Musterbild für die Anlage eines Enkomions gilt die

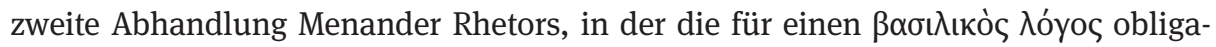
torischen Kompositionselemente erläutert werden ${ }^{55}$ - Proömion, Abstammung und Heimat, Geburt, Aussehen, Erziehung und Bildung, Charaktereigenschaften, Taten und Leistungen in Krieg und Frieden sowie ein Epilog mit positiven Zukunftsaussichten -, wobei nicht nur Personen, sondern auch Tiere und Pflanzen sowie Gegenstände, Orte und Zeiten Lob erfahren können.

Wesentlich zum Verständnis der Umsetzung rhetorischer Prinzipien in der spätantiken Dichtung ist zudem die Herausbildung eigener enkomiastischer Literaturformen in der Dichtung selbst: Das Prosa-Enkomion der Sophistik des 5. Jhs. v. Chr. findet seine Entsprechung in der frühgriechischen Poesie eines Bakchylides oder Simonides sowie in den Epinikien Pindars. ${ }^{56}$ Die Systematisierung und Strukturierung enkomiastischer Elemente in der sophistischen Prosa hat die Herausbildung eines eigenen Genus zum Ergebnis, das seinerseits wiederum auf andere Literaturgattungen Einfluss nimmt. Mit dem Aufkommen der Sophistik ermöglicht die Breitenwirkung rhetorischer Prosa-Enkomien ihrerseits einen Transfer der Kategorie Enkomion in die Dichtung und zeugt von der gegenseitigen Beeinflussung beider Gattungen.

Vor diesem Hintergrund muss die Verarbeitung des Genus Enkomion durch Nonnos von Panopolis in den Dionysiaka gesehen werden. Der Dichter erzählt die Lebensgeschichte und den kontinuierlichen Aufstieg des Weingottes, wobei einzelne Stationen seines Wirkens thematischen Rubriken des Enkomions zugeordnet werden können, ohne jedoch das Enkomion-Schema, wie es Menander Rhetor bietet, zur Gänze umzusetzen. Er verfährt vielmehr äußerst selektiv und wendet lediglich einzelne dem Genus Enkomion zuzurechnende Elemente an, stets mit der Absicht, den Protagonisten seines Werkes in Szene zu setzen. Innerhalb des groß angelegten Enkomions auf Dionysos erfüllt auch die Ampelos-Episode ihren narrativen Zweck: In der

52 Neben Enkomien und Psogoi auf mythische und historische Figuren wie Diomedes, Odysseus und Demosthenes finden sich in den Progymnasmata des Libanios auch solche auf abstrakte Begriffe wie die Gerechtigkeit oder auf Sachverhalte und Tätigkeiten aus dem Alltagsleben wie die Landwirtschaft und das Nutztier Rind, vgl. Gibson (2008) 195 - 319.

53 Vgl. die Edition der erhaltenen Fragmente durch Heitsch (1961) und Heitsch (1964), außerdem Trypanis (1981) 398.

54 Vgl. Cribiore (2001) $229 \mathrm{f}$.

55 Men. Rh. 2,368 - 377; vgl. Clark (1957) 194-198; Viljamaa (1968) 98f.; Pernot (1993) 134-178;

Kennedy (1994) 205; Andersen (2001) 246; Cribiore (2001) $228 \mathrm{f}$.

56 Vgl. Bergk (1883) 169-171; RE V/2, 2581 - 2583; Trypanis (1981) 397. 
Biographie des Gottes handelt es sich um sein erstes Wirken als jugendlicher Gott, die Bücher 10-12 stellen folglich eine Schlüsselpassage im Epos dar, in der Dionysos erstmals zusammen mit seinem Hauptattribut, dem Wein, in Erscheinung tritt und eine signifikante Entwicklung zu einem allgemein anerkannten Gott erfährt.

Die Affinität der Ampelos-Episode zum Genus Enkomion wird im Folgenden anhand ausgewählter Passagen, insbesondere der Reden der Schicksalsgöttin Atropos (Nonn. D. 12,142-171) und des Dionysos (207-289), diskutiert. Beide, Atropos und Dionysos, halten einen Lobpreis auf den verstorbenen Satyrn, auf die neue Pflanze sowie auf den Weingott selbst. Dargestellt wird die Art und Weise, wie Nonnos das Enkomion-Schema in der Mikrostruktur seines Epos anwendet, welcher sprachlicher Elemente er sich bedient und welches narrative Ziel er mit der Aufnahme dieses Genus verfolgt.

\section{Ein Enkomion auf Ampelos}

Als feststehende Grundschemata für das Enkomion finden sich in den kaiserzeitlichen Progymnasmata folgende Rubriken: Abstammung und Familie, Erziehung, Aussehen, Leistungen sowie gegebenenfalls auch die Todesumstände. ${ }^{57}$ Die erste Figur, auf die in der Ampelos-Episode eines dieser Elemente angewandt wird, ist Ampelos selbst,

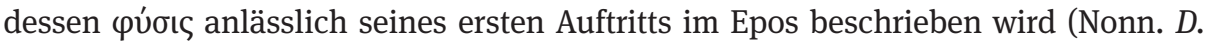

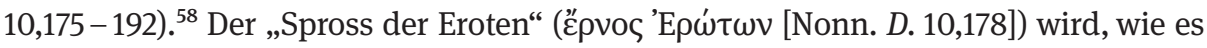
der literarischen Konvention entspricht, vom Kopf bis zu den Füßen beschrieben: Kinn, Wangen, Haar, Rücken, Hals, Mund, Stimme, Gliedmaßen, Füße und als Nachtrag die Augen. Besonders hervorgehoben werden die Schönheit des Gesichts die zarte Röte von Kinn und Mund - sowie das Strahlen der Gliedmaßen, Füße und Augen. Ampelos ist hier ganz sterblicher Satyr, Dionysos' auserwählter Begleiter, der sich von den anderen durch seine körperlichen Vorzüge abhebt und dessen erotische Ausstrahlung Dionysos wie ein Blitz trifft. Die lobenden Worte, die Ampelos für sein Aussehen erhält, setzen die Liebesgeschichte zwischen dem Gott und seinem Lieblingssatyrn in Gang. Die Ampelos-Episode verspricht an dieser Stelle insofern ein Stück erotische Literatur zu werden, als es sich bei der Figurenbeschreibung um einen gängigen Topos der erotischen Dichtung und der Romanliteratur handelt. ${ }^{59}$ Die folgenden Ereignisse bis zu den sportlichen Wettkämpfen erfüllen diese Erwartung, da Dionysos sogar Ampelos' negativen Eigenschaften etwas Positives abgewinnt (Nonn. D. 10,267-269) und da das gesteigerte Interesse des Gottes die Eifersucht eines Konkurrenten schürt (278-289). Mit diesem Porträt nimmt Nonnos nicht nur die erotische

57 Vgl. Aphth. Prog. 8; Hermog. Prog. 7; Nicol. Prog. 47 - 58 Felten; siehe auch Pernot (1993) 148; zur Rubrik Aussehen auch Men. Rh. 2,371,14-17; Nicol. Prog. 50,7 Felten; Pernot (1993) 159-161.

58 Zu Ampelos' Porträt siehe Kap. 3.3.

59 Vgl. z. B. das Porträt Leukippes in Ach. Tat. 1,4; zum Einfluss des Romans auf Nonnos siehe Kap. 5.4 . 
Literatur in die Dionysiaka auf, sondern arbeitet mit dem Lob der Weinpflanze auch auf das narrative Ziel seiner Ampelos-Episode hin. In der Ekphrasis der Ampelos-Figur werden die Eigenschaften des späteren Getränks vorweggenommen: das Wort ع̋pvoৎ

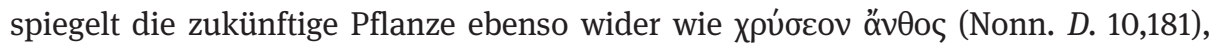

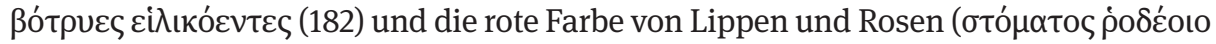

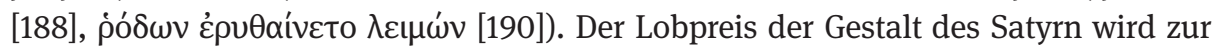
Vorstufe des Lobpreises auf das neue Getränk.

Unmittelbar auf die Beschreibung seines Äußeren folgt ein weiterer Baustein des Enkomions auf Ampelos: In seiner ersten Rede in den Dionysiaka fragt Dionysos nach Ampelos' Herkunft, seinem yévos (Nonn. D. 10,193-216). ${ }^{60}$ Die Antwort darauf wird nicht sofort gegeben, Dionysos entwickelt stattdessen aus der ursprünglichen Frage nach der Familie des Satyrn seine eigene Genealogie von Zeus her, die er zum Maßstab für seine Einschätzung bezüglich der Herkunft des Ampelos nimmt (Nonn. D. 10,208-

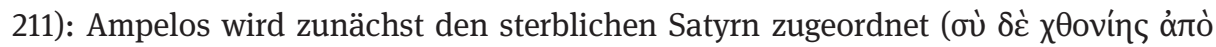

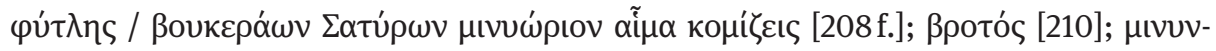

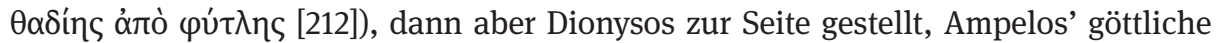

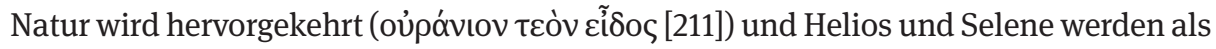

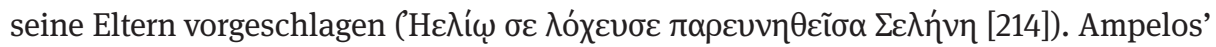
Schönheit, die durch den Vergleich mit verschiedenen Göttern zum Ausdruck gebracht wird (Nonn. D. 10,196-202), spreche zudem für sein göttliches Wesen. Beispiellos ist die von Nonnos konstatierte Abstammung des Ampelos von Helios und Selene. ${ }^{61}$ Auch hierin verfolgt der Dichter offenbar seinen eigenen Weg und wählt die potentiellen Eltern im Hinblick auf die Stilisierung des Satyrn als strahlende Schönheit, die Abstammung von den beiden Licht spendenden Gottheiten begründet die vorangegangene Glanz-Motivik.

Aufschlussreich für das Verständnis von Ampelos’ yévoৎ ist das Thema Blut am Ende der Dionysos-Rede, welches durch das dreimal gesetzte Wort $\alpha \tilde{\mu} \mu \alpha$ in den Mit-

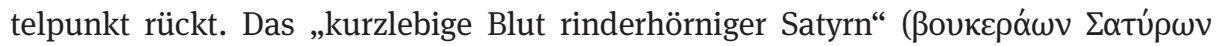

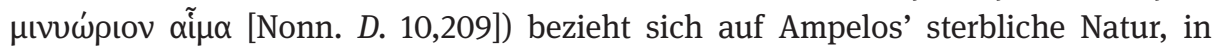

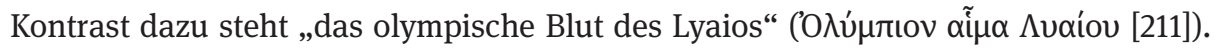
Abermals wird Ampelos' Wesen thematisiert, wenn in Nonn. D. 10,213 wiederum von

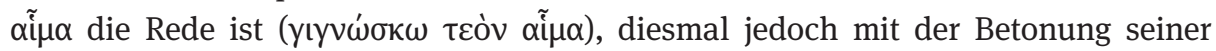
göttlichen Natur. Das rote Blut, das in der Dionysos-Rede genannt wird, nimmt typologisch Ampelos' Metamorphose in die Weinpflanze sowie die Genese des Weines vorweg, das Genus Enkomion dient Nonnos hier als Verweis auf das narrative Ziel der Episode. $^{62}$

60 Zu diesem Element des Enkomions vgl. Men. Rh. 2,370,9-28; zur Dionysos-Rede siehe auch Kröll (2014).

61 Zur ungewöhnlichen Verbindung von Helios und Selene vgl. Chrétien (1985) 145 Anm. ad 214; Gigli Piccardi (2003) 705f. Anm. ad 214-216.

62 Diese Stelle birgt einen weiteren wesentlichen Aspekt zum Verständnis der Ampelos-Episode: Den eigentlichen Kern bildet Dionysos’ Selbstidentifikation als Zeussohn und somit die Bestätigung seines 


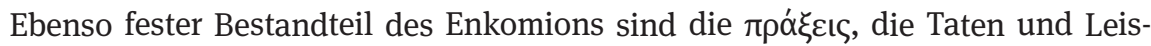
tungen der gepriesenen Person, ${ }^{63}$ eine Rubrik, die Nonnos durch die Einfügung zweier katalogartiger Passagen mit den unterschiedlichen Tätigkeiten des Satyrn bedient (Nonn. D. 10,217-249;11,99-112): Ampelos hält sich bevorzugt in der freien Natur auf

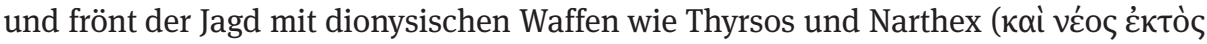

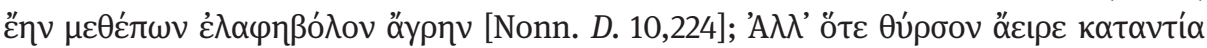

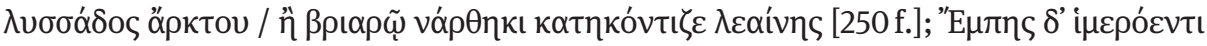

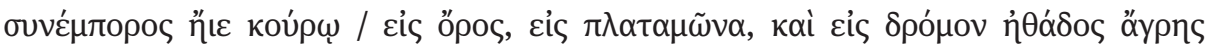

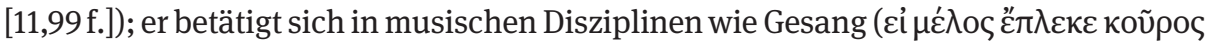

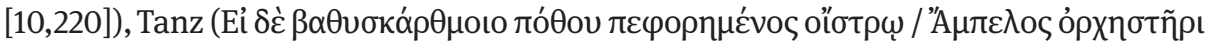

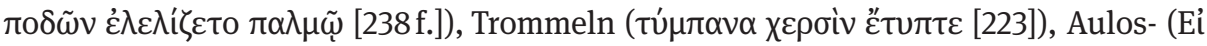

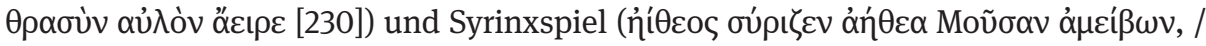

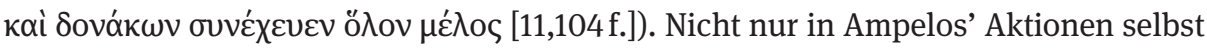
sind die typisch dionysischen Kultelemente vorweggenommen, sondern auch die von Dionysos ob der Tätigkeiten seines Lieblings empfundene Freude verweist auf die Verbindung des Weingottes mit den dionysischen Kulthandlungen, welche ihm, so er einmal ein anerkannter Gott ist, von seinen Anhängern künftig entgegengebracht werden. ${ }^{64}$

Die besonders enge Verquickung von Satyr, Wein und Gott zeigt sich auch auf dem

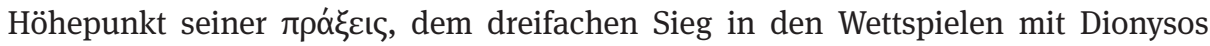
(Nonn. D. 10,321-430;11,1-55). Obwohl die Ausgangslage denkbar ungleich ist, gelingt der Sieg des Satyrn durch Dionysos' Wohlwollen und Eingreifen. Die physische Leistung des Satyrn wird relativiert durch die Aufbietung göttlicher Macht und Wirkkraft, der Lobpreis des Satyrn entwickelt sich zum Lobpreis der neuen Pflanze und des ihr zugehörigen Gottes.

Als letztes enkomiastisches Element für Ampelos werden seine Todesumstände

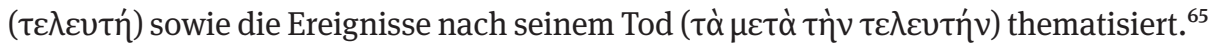
Mit dem selbst verschuldeten Sturz vom Stier und der Verwandlung in eine Weinrebe (Nonn. D. 11,113-223) greift Nonnos das Genus des Epitaphios oder der laudatio funebris auf und gibt zusätzlich zur Darstellung der Todesumstände auch einen Ausblick auf die unmittelbare und fernere Zukunft des Betrauerten. ${ }^{66}$ Ampelos' Tod bildet

göttlichen Status; was zunächst als Teil eines Enkomions auf Ampelos beginnt, entwickelt sich sukzessive zu einem Hymnus auf den Gott. Nonnos schwankt in der Dionysos-Rede bewusst zwischen Enkomion und Hymnus, vgl. dazu S. $145 \mathrm{f}$.

63 Vgl. Men. Rh. 2,372,12-2,376,24; Pernot (1993) 165-176.

64 Bezeichnend für die Modulationen, die Nonnos am homerischen Epos vornimmt, ist der Einsatz der genannten dionysischen Attribute als Angriffs- und Verteidigungswaffen im Krieg gegen die Inder. Dionysos verzichtet auf die für das Epos typischen Waffen wie Schwert und Schild und erreicht stattdessen mit Weinranken und Wein eine gleichsam friedliche Eroberung Indiens, vgl. dazu Shorrock (2007) $390 f$.

65 Vgl. Pernot (1993) 176-178.

66 Auch Menander Rhetor schlägt vor, als Epilog eines Enkomions einen Blick in die Zukunft zu gewähren; als positive Aspekte der Regierungszeit sollten insbesondere das Wohl der Städte und ihrer 
keineswegs den Endpunkt des Enkomions, sondern wird um die anschließende Metamorphose und somit um den Ausblick auf das neue Zeitalter des Weines erweitert, der die Biographie des Satyrn beschließt und gleichzeitig die des Weines und seines Gottes eröffnet.

\section{Ein Enkomion auf den Wein}

Nonnos entwickelt aus dem anfänglichen Enkomion auf den Satyrn Ampelos ein Enkomion auf den Wein, indem er verteilt über die Bücher 10-12 wiederholt Kategorien des Enkomions auf die neue Pflanze anwendet. Damit stellt sich der Dichter in eine lange Tradition der Enkomien und Psogoi auf Pflanzen, die in der rhetorischen Prosa der Kaiserzeit fest verankert ist, so etwa bei Libanios in seinen Progymnasmata ein Enkomion auf die Dattelpalme und den Apfelbaum (Lib. Prog. Enkom. 9 Gibson): Neben dem bevorzugten Ort (Lib. Prog. Enkom. 9,2 Gibson) werden auch die zugehörigen Gottheiten (Lib. Prog. Enkom. 9,1 Gibson), das Aussehen der Pflanze (Lib. Prog. Enkom. 9,4-6 Gibson), die Zeit des Wachstums (Lib. Prog. Enkom. 9,3 Gibson), Anwendungsbereiche und Nutzen (Lib. Prog. Enkom. 9,7-9 Gibson) sowie in einer Synkrisis ihre jeweiligen Vor- und Nachteile genannt (Lib. Prog. Enkom. 9,10 Gibson). Auch die übrigen kaiserzeitlichen Progymnasmata schlagen vor, neben Personen, Zeiten, Orten, Tieren und Unbeseeltem auch Pflanzen zum Gegenstand von Enkomien zu machen. ${ }^{67}$ Wesentliche Elemente bilden zudem die Synkriseis, die Vergleiche, die allenthalben angewandt werden können. Nicht nur bei Libanios, sondern auch bei anderen Rhetoren ist die Pflanzenwelt ein beliebter Gegenstand für Enkomien, etwa die Rose bei Aphthonios, der ein mythologisches Aition ihrer roten Farbe gestaltet (Apht. Prog. 2,5), bei Prokopios von Gaza, der fünf seiner sieben Deklamationen damit schließt (Procop. Gaz. Op. I [= Dial. 1], Op. II [= Dial. 2], Op. IV [=Ethop. 1], Op. V [= Ethop. 2], Op. VI [= Ethop. 3]) und in einer die Rose selbst zum Thema macht (Op. III [= Dial. 3]), sowie auch bei Chorikios von Gaza (Chor. XVI [= Dial. 9] und XXXIX [= Dial. 24] Foerster u. Richtsteig). ${ }^{68}$

Mit denselben Mitteln wie das Enkomion operiert auch der Psogos, die Invektive oder Tadelrede, die dasselbe Kompositionsschema aufweist und sich nur hinsichtlich

Einwohner, die Pflege der religiösen Kulte, das Fehlen jeglicher kriegerischer Aktivitäten und der Überfluss an Nahrungsmitteln hervorgehoben werden, eine abschließende Bitte um eine möglichst lange Herrschaftszeit sollte die Lobrede abrunden, vgl. Men. Rh. 2,377,9-30.

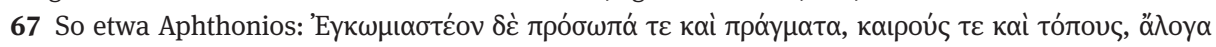

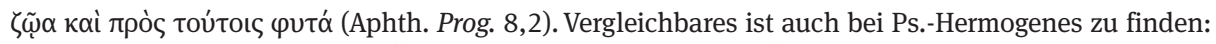

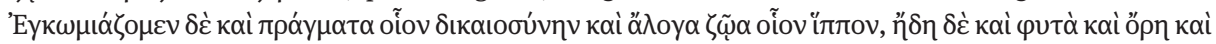

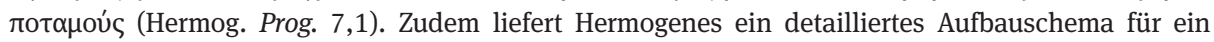
Pflanzen-Enkomion (Hermog. Prog. 7,14): Lebensraum, zugehörige Gottheit, Kultivierung, Pflegeaufwand, Aussehen und Nützlichkeit; zu diesem Schema vgl. auch Pernot (1993) 238- 249.

68 Vgl. Ciccolella (2000) LVf.; zur Poetik der Ekphrasis bei Chorikios vgl. auch Greco (2007). - Für ein Enkomion auf die Rose siehe auch Ach. Tat. 2,1. 
der vorgenommenen Wertung von der Lobrede unterscheidet. Besondere Charakteristika der Pflanze können im einen Fall zum Vor-, im anderen zum Nachteil ausgelegt werden. Ein weiteres Stück des Libanios, ein Psogos auf den Weinstock (Lib. Prog. Invec. 8 Gibson), ist für die Ampelos-Episode und die Umsetzung rhetorischer Techniken von besonderem Interesse, da dieselben Argumente der Lobrede nun für den Tadel verwendet werden: die kümmerliche Gestalt des Weinstocks (Lib. Prog. Invec. 8,3-5 Gibson), die verheerende Wirkung des Weines, der für Trunkenheit, Kriminalität, Revolten sowie Ineffizienz bei der Arbeit verantwortlich sei (Lib. Prog. Invec. 8,7-12 Gibson). ${ }^{69}$ Als prominentes mythisches Beispiel dafür wird Ikarios genannt, der durch die unvorhersehbare Wirkung des Weines den Tod gefunden habe (Lib. Prog. Invec. 8,2 Gibson); zudem würden die aus der Pflanze gewonnenen Produkte keinesfalls den hohen Pflege- und Kultivierungsaufwand rechtfertigen (Lib. Prog. Invec. 8,6 Gibson), insbesondere im Vergleich mit dem bei weitem genügsameren und dennoch wertvolle Frucht hervorbringenden Ölbaum (Lib. Prog. Invec. 8,13 Gibson). Dass Nonnos mit der Anwendung des rhetorischen Genus Enkomion auf sein Werk kein Neuland beschreitet, wird auch aus dem Umgang mit rhetorischen Genera durch spätantike Dichter ersichtlich: So finden sich etwa in den anakreontischen Dichtungen des Johannes von Gaza (6. Jh. n. Chr.) zwei Enkomien auf den Frühling mit all seinen Vegetation hervorbringenden Kräften (Jo. Gaz. anacr. 4 und 5 Ciccolella [2000] 146$159)^{70}$ und auch die Rosen-Gedichte des Georgios Grammatikos erklären Pflanzen zum Gegenstand des Lobes. ${ }^{71}$

Auch in den Büchern 10 - 12 der Dionysiaka bildet mit dem Weinstock eine Pflanze die narrative Leitlinie, wobei sich nirgendwo ein geschlossenes Schema des Enkomions findet, sondern Nonnos selektiv verfährt, einzelne Elemente auswählt und diese über die Ampelos-Episode verteilt. Neben bevorzugtem Lebensraum, Aussehen und Eigenschaften werden auch einzelne Anwendungsbereiche des Weines indirekt vorweggenommen: Das Spiel der Satyrn am und im Paktolos in Nonn. D. 10,139-174 beschreibt Heimat und künftigen Standort der Weinrebe und entspricht der ersten Rubrik, die Menander Rhetor nach dem Proömion empfiehlt (Men. Rh. 2,369,18-2,370,8). Die $\pi \alpha \tau$ ís des Weines, der lydische Fluss, bildet nicht nur den Rahmen für die Wasserspiele der Satyrn, sondern ist auch Ort für sämtliche Entwicklungen rund um Dionysos und Ampelos. Statt daran die Kategorie Familie und Abstammung anzuschließen, findet sich bei einem Enkomion auf Pflanzen ihr mythischer Erfinder, der meist mit der zugehörigen Gottheit gleichgesetzt wird. Die Provenienz des Weinstocks in der Ampelos-

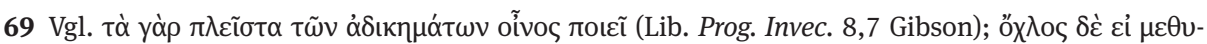

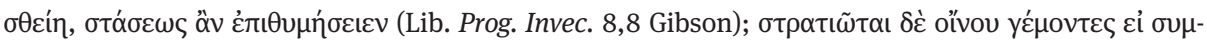

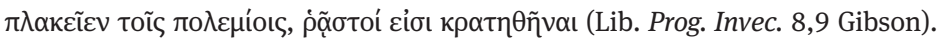

70 Johannes von Gaza ist insbesondere für seine Ekphrasis von Gemälden in Gaza bekannt, die eine tabula mundi mit 60 teils allegorischen Figuren wiedergeben, vgl. Gigli Piccardi (2011). - Enkomien und Psogoi auf den Wein finden sich auch in der Lobrede einer Platane auf eine an ihr emporwachsende Weinrebe in AP 9,231 sowie in einem Psogos auf eine noch unreif gepflückte Weintraube in AP 9,375. 71 Siehe [Georg. Gramm.] 1-6; Ciccolella (2000) 180-237. 
Episode ist mit der Geburt aus dem Satyrn Ampelos und der Zuordnung zur dionysischen Sphäre klar definiert, das Enkomion des Satyrn mit der Beschreibung der rötlichen Farbe seiner Wangen und der traubenförmig fallenden Haarsträhnen wird zugleich ein Lob der künftigen Pflanze. Die Vorwegnahme der Eigenschaften der Weinpflanze in der Ampelos-Figur äußert sich zudem in der Ringkampfszene, in welcher Ampelos durch seine Ringergriffe das typische Wesen einer Kletterpflanze an

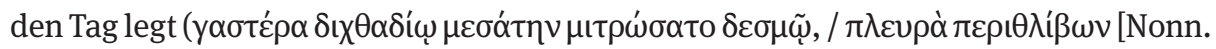
D. 10,369f.]). In der sportlichen Überlegenheit des Ampelos über seine Konkurrenten spiegelt sich die herausragende Stellung des Weines gegenüber anderen Pflanzen, und schließlich antizipiert Ampelos' Verbindung mit dem Fluss Paktolos die antike Gepflogenheit des Mischens von Wasser mit Wein.

Einen Höhepunkt erreicht das Enkomion auf die Weinrebe mit der Intervention der Moire Atropos, welche dem immer noch um Ampelos trauernden Dionysos den unsterblichen Ruhm des Satyrn und der aus ihm hervorgehenden Pflanze prophezeit, um ihm Trost zu spenden (Nonn. D. 12,138-172):

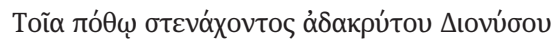

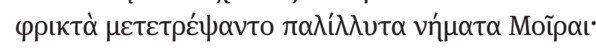

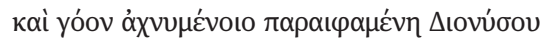

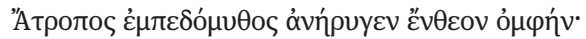

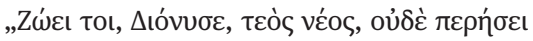

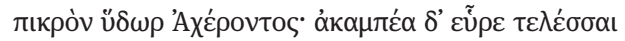
бòs yóos ảं

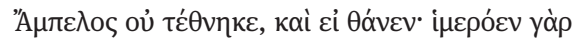

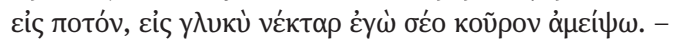

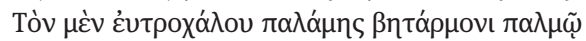

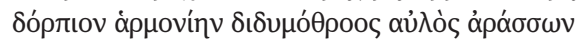

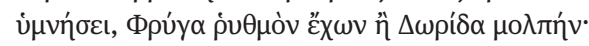

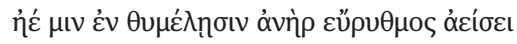

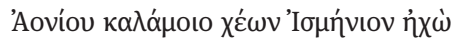

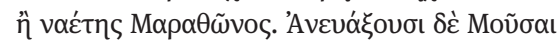
”А

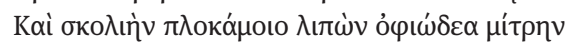

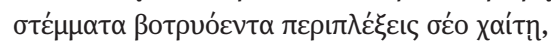

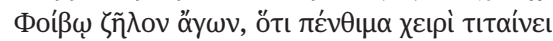

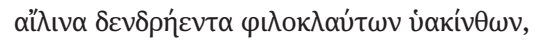

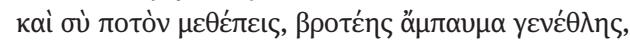

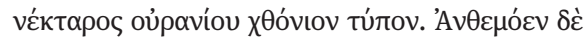

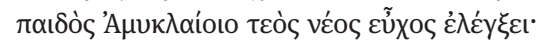

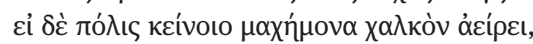

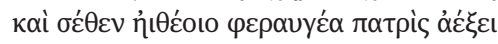

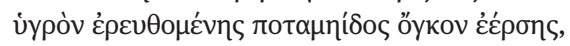

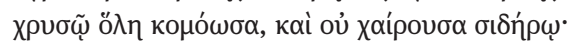

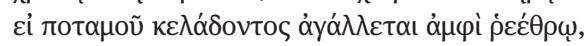

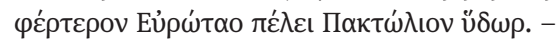
”А

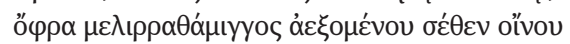

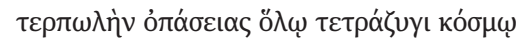




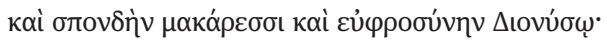

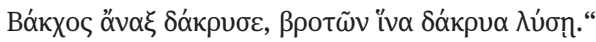

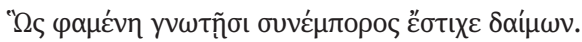

So voll der Sehnsucht seufzte der tränenlose Dionysos. Da trennten die Moiren die schaurigen Schicksalsfäden wieder auf und wandten sie um. (140) Und den Kummer des wehklagenden Dionysos überstimmte Atropos, die Unverbrüchliche, und ließ ihre göttliche Stimme erklingen: „Dionysos! Es lebt dir dein Jüngling, denn er durchquerte nicht das herbe Wasser des Acheron! Dein Kummer über die unbeugsamen Fäden der unerbittlichen Moire soll ein Ende finden! Sie sind widerrufen! (145) Ampelos ist nicht tot, auch wenn er gestorben ist! Denn in einen lieblichen Trank, in süßen Nektar werde ich deinen Knaben verwandeln! - Ihn wird im pulsierenden Rhythmus der sich flink bewegenden Hand der tönende Doppelaulos mit seiner Melodie am Mittagstisch preisen, mit einem phrygischen Rhythmus oder einem dorischen Lied. (150) Und ihn wird am Herd ein Mann rhythmisch besingen, indem er seiner aonischen Rohrflöte einen ismenischen Klang entlockt, oder ein Bewohner Marathons. Und die Musen werden ihn ehren, den lieblichen Ampelos, zusammen mit dem weinstockreichen Lyaios. Und du wirst den gewundenen Schlangenkranz aus deinen Locken nehmen, (155) dir Binden aus Weinlaub um dein Haar flechten und sogar bei Phoibos Neid hervorrufen, weil er nur mit der Hand nach den schmerzvollen, zu einer Pflanze gewordenen Trauerrufen der tränenliebenden Hyazinthen greift. Und du erhältst den Trank, die Aufhebung deiner sterblichen Herkunft, irdisches Abbild des himmlischen Nektars. Als Blütenpflanze (160) wird dein Jüngling den Ruhm des Knaben aus Amyklai übertreffen. Und wenn seine Stadt das kriegerische Erz erhebt und die glänzende Heimat deines Jungen den feuchten Schwall des rötlichen Flusstaus mehrt, ganz mit Gold geschmückt, und sich nicht am Erz erfreut, (165) wenn es in der Strömung des brausenden Flusses überall glänzt, dann ist das Wasser des Paktolos stärker als das des Eurotas! Ampelos! Schmerz bereitest du dem Dionysos, der den Schmerz nicht kennt, damit du, wenn aus dir der honigtriefende Wein wächst, dem ganzen vierfachen Kosmos Freude bereitest (170) als ein Opfer für die glückseligen Götter und zur Freude für Dionysos. Bakchos, der Herr, weinte, um die Tränen der Menschen zu lösen.“ So sprach die Gottheit und ging zusammen mit ihren Schwestern weg.

Der Tenor der Atropos-Rede ist unmissverständlich: Ampelos wird nach dem Willen der sonst unbeugsamen Moiren auferstehen, der Wein wird überall in der Welt berühmt sein und Dionysos göttliche Qualitäten verleihen, welche ihn sogar über andere olympische Götter heben werden. ${ }^{72}$ Nonnos komponiert die Rede zwar nicht exakt nach den Vorgaben, die die Progymnasmata für ein Enkomion auf eine Pflanze vorsehen, setzt aber einzelne Bauelemente gezielt ein: Die Verse Nonn. D. 12,142-146 rücken das Thema Geburt des Weinstocks ins Zentrum, wenn Ampelos' Tod mit der Genese des Weines verknüpft wird und Atropos ewiges Leben für den Satyrn erwirkt. ${ }^{73}$ Während Ampelos als Erfinder des Weines am Ende der Rede abermals namentlich genannt wird (Nonn. D. 12,167), bilden die Auswirkungen, die die Geburt des Weines nach sich zieht, die Anwendungsbereiche der Pflanze und ihres Saftes sowie die

72 Zum proleptisch verwendeten Adjektiv $\pi \alpha \lambda^{\prime} \lambda \lambda \nu \tau \tau 0 \varsigma$ bei Nonnos vgl. Spanoudakis (2014b) 309f. Anm. ad 177d.

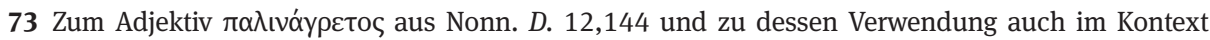
anderer Auferstehungsszenen bei Nonnos siehe Spanoudakis (2014b) 194 Anm. ad 47c; zum Kontrast Tod vs. Leben in Nonn. D. 12,145 vgl. Spanoudakis (2014b) 223 f. Anm. ad 85b. 
Betonung ihrer Nützlichkeit für die Menschheit den Hauptteil des prophetischen Enkomions: Der Wein wird als Begleiter musikalischer Darbietungen und als tonangebende Kraft bei Symposien, Gastmählern und Theatervorführungen zusammen mit dem Gott den Vorsitz dieser kollektiven Ereignisse stellen (Nonn. D. 12,147-153) und ein weiteres dionysisches Produkt, den Kranz aus Weinlaub, hervorbringen (154f.). Die fundamentalen Auswirkungen des Weines auf das Leben der Menschen, die beruhigende und lindernde Wirkung (Nonn. D. 12,162-166, 167-172), verdichten sich am Ende der Rede in einer Synkrisis: Der Vergleich des Weinstocks mit Apolls Hyazinthe geht aufgrund der Möglichkeit der Herstellung eines bekömmlichen Getränks zugunsten des Ersteren aus, wohingegen Apoll mit einer fruchtlosen Blume vorlieb nehmen muss (Nonn. D. 12,156-160). Der Dichter benutzt das Genus Enkomion, um noch vor der Verwandlung des Satyrn auf den narrativen Höhepunkt der AmpelosEpisode, die Ausstattung des Dionysos mit seinem Hauptattribut, hinzuarbeiten.

Zur Vollendung gelangt das Loblied auf die Pflanze in der unmittelbar auf die Rede der Atropos folgenden Metamorphose, in der die minutiöse Aufzählung der einzelnen sich verwandelnden Körperpartien des Satyrn gleichzeitig das Porträt des Weinstocks

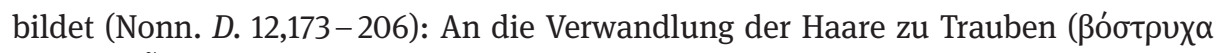

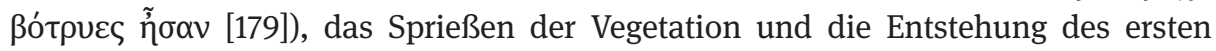
Weingartens (185-187) schließen die erste Weinlese, Pressung und Verkostung an, welche von Dionysos persönlich durchgeführt werden (193-206). Sogleich nach der Entstehung der Pflanze wird diese mit dem für sie vorgesehenen Gott verbunden, ihre Abstammung und Zugehörigkeit sind eindeutig festgelegt. Die Einführung des Weinstocks im 12. Buch der Dionysiaka erfolgt analog zur erstmaligen Vorstellung des Ampelos im 10. Buch, das Enkomion auf den Satyrn wird zum Enkomion auf den Wein.

\section{Ein Enkomion auf den Wein und auf Dionysos}

Die enkomiastischen Elemente gipfeln in der letzten Rede des Dionysos der AmpelosEpisode, in der er ein insgesamt 82 Verse umfassendes Bekenntnis zu seinem göttlichen Wesen und seinem Kult liefert. ${ }^{74}$ Was als Enkomion auf Ampelos beginnt, entwickelt sich sukzessive zu einem Preis des Weines und des Gottes selbst (Nonn. D. 12,207-291):

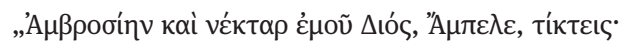

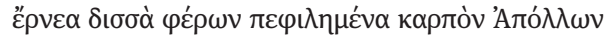

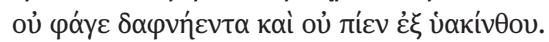

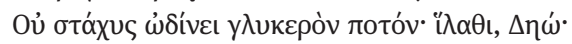
210

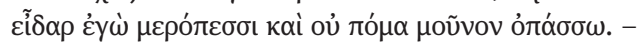

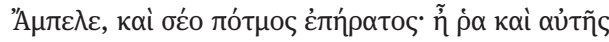

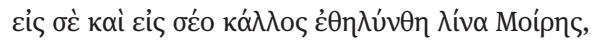

74 Zur Klassifizierung der Rede als Enkomion vgl. Vian (1995a) 204 (555). 


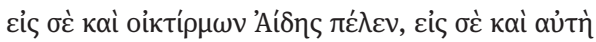

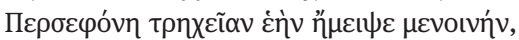

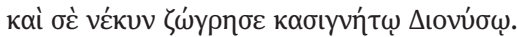

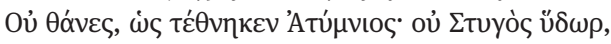

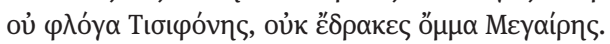

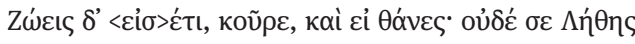

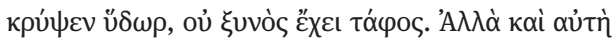

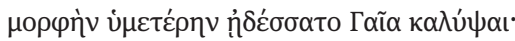

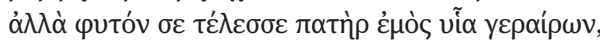

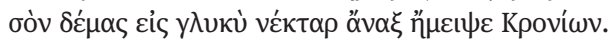

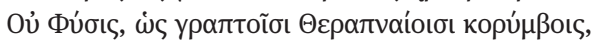

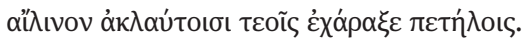

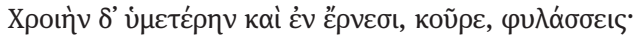

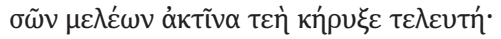

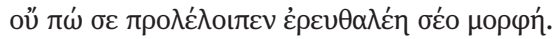

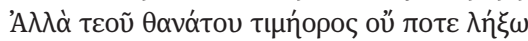

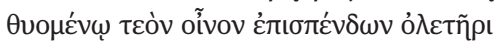

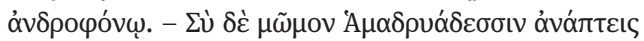

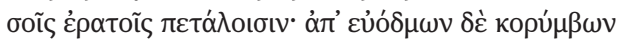

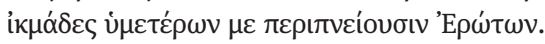

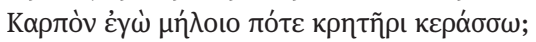

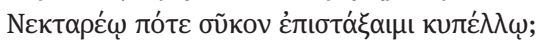

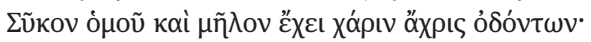

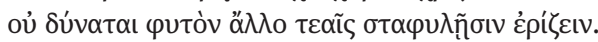

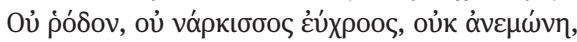

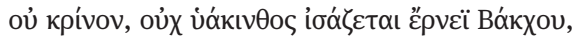

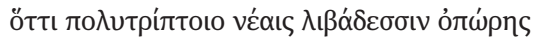

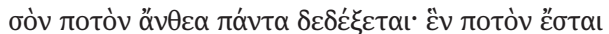

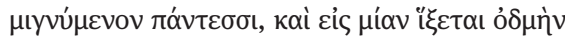

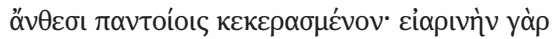

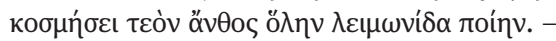

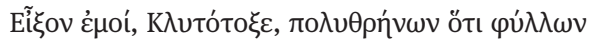

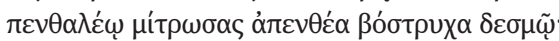

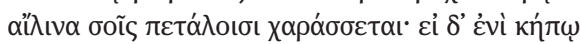

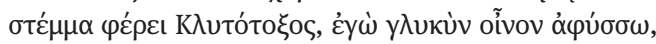

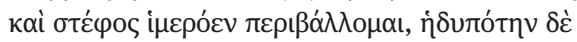

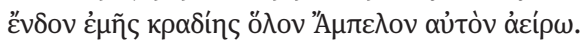

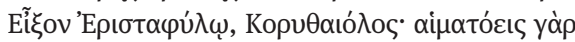

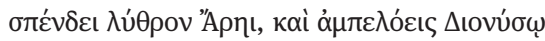

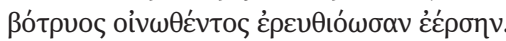

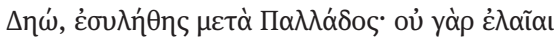

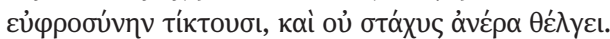

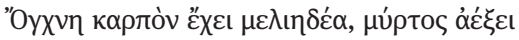

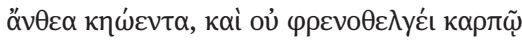

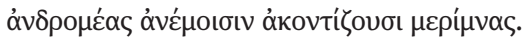

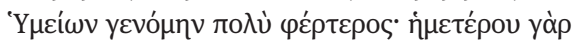

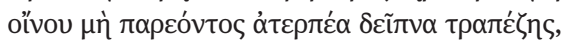

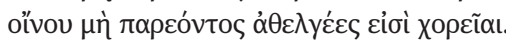

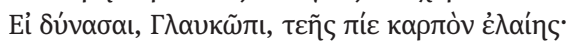

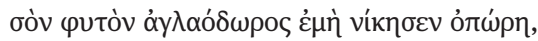




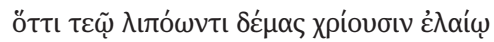

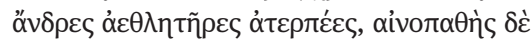

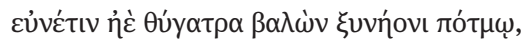

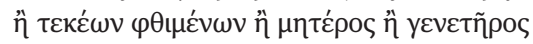

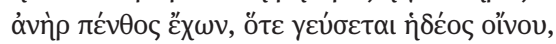

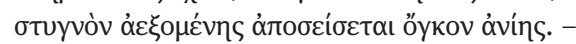

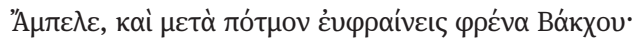

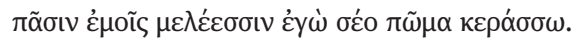

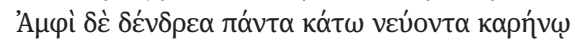

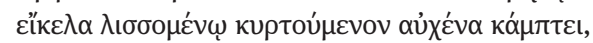

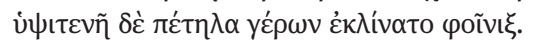

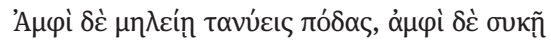

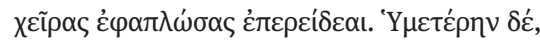

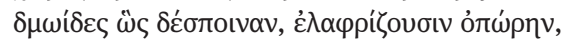

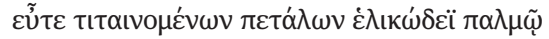

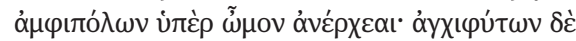

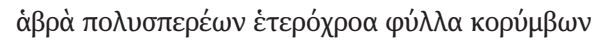

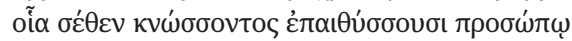

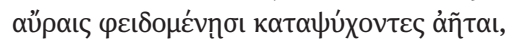

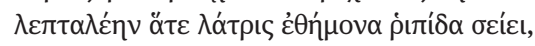

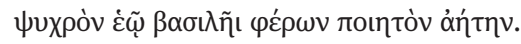

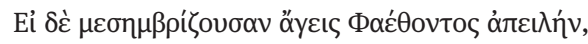

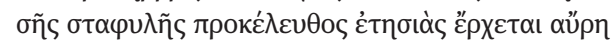

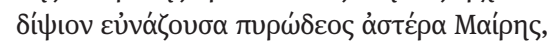

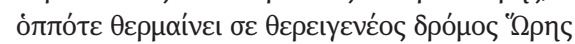

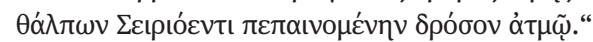

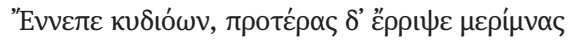

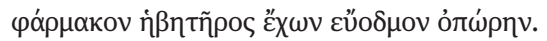

„Ambrosia und Nektar meines Zeus lässt du, Ampelos, entstehen! Apollon, der zwei innig geliebte Sprösslinge hervorbrachte, konnte die Frucht des Lorbeers nicht essen, und aus seiner Hyazinthe konnte er nicht trinken. (210) Auch die Getreideähre bringt keinen süßen Saft hervor - sei gnädig, Demeter! Ich werde den Menschen auch Nahrung und nicht nur ein Getränk verschaffen.

Ampelos, auch du wirst ein ähnliches Geschick haben! Ja, sogar die Schicksalsfäden der Moira selbst ließen sich durch dich und durch deine Schönheit erweichen! Durch dich erbarmte sich auch Hades, durch dich änderte sogar (215) Persephone selbst ihr wildes Verlangen und erweckte deinen Leichnam für ihren Bruder Dionysos wieder zum Leben! Du bist nicht gestorben, wie Atymnios gestorben ist! Du hast nicht das Wasser der Styx, nicht die Flamme der Tisiphone, nicht das Auge der Megaira gesehen. Du lebst noch, Knabe, auch wenn du gestorben bist! Und dich verbarg (220) das Wasser der Lethe nicht, und auch kein Grab hält dich fest, wie alle anderen, sondern gar die Erde selbst scheute sich davor, deinen Leib zu bedecken. In Gestalt einer Pflanze brachte dich mein Vater zur Vollendung, zur Ehre seines Sohnes, und deine Gestalt verwandelte der Herrscher, der Kronide, in süßen Nektar. Die Natur ritzte nicht, wie auf den beschriebenen Blütenblättern aus Therapnai, (225) eine Wehklage in deine Blätter ein, sie bleiben ohne Tränen. Deine Hautfarbe bewahrst du auch auf deinen Schösslingen, Knabe! Dein Ende verkündete den Glanz deiner Glieder; dein rötliches Äußeres schwand dir noch nicht. Doch niemals werde ich als Rächer deines Todes aufhören, (230) deinen Wein bei der Schlachtung deines männertötenden Mörders zu spenden.

Du wirst Schamesröte bei den Hamadryaden hervorrufen mit deinen lieblichen Blättern. Denn von den gut duftenden Trauben herab umwehen mich die Ströme deines Liebreizes. Werde ich je die Frucht des Apfels im Mischkrug mischen können? (235) Werde ich jemals die Feige in einen Nektar- 
Becher träufeln? Die Feige bereitet gleich wie der Apfel nur bis zu den Zähnen Freude. Eine andere Pflanze ist nicht imstande, mit deinen Trauben zu konkurrieren! Es gleicht nicht die Rose, nicht die schönfarbige Narzisse, nicht die Anemone, nicht die Lilie, nicht die Hyazinthe dem Spross des Bakchos, (240) weil mit den frischen Tropfen der fein zerriebenen Traube alle Blüten deinen Trank aufnehmen werden. Ein einziger Trank wird es sein, der sich mit allen vermengt. Zu einem einzigen Wohlgeruch wird er sich vereinen und sich mit mannigfachen Blüten mischen, denn deine Blüte wird die ganze grasige Frühlingsflur schmücken!

(245) Weiche zurück vor mir, Bogenberühmter, denn du hast dir der vielklagenden Blätter schmerzlose Ranken aufgesetzt zu einem schmerzvollen Band! Die Wehklagen sind in deine Blätter eingeritzt! Und wenn im Garten der Bogenberühmte den Kranz trägt, dann schöpfe ich den süßen Wein und winde mir ein liebliches Band um, und als süßen Trank (250) nehme ich Ampelos selbst ganz in mein Herz auf. ${ }^{75}$ Weiche zurück vor dem Traubenreichen, Helmbuschschüttler! Denn blutig spendet er dem Ares den Trank, und der Weinstockreiche den rötenden Saft der Weintraube dem Dionysos. Deo! Du bist zusammen mit Pallas entwaffnet! Denn die Olivenbäume bringen keinen (255) Frohsinn hervor, und die Kornähre erfreut den Mann nicht. Die Birne hat eine honigsüße Frucht, die Myrte lässt ihre flammenartigen Blüten wachsen, aber sie schmettern mit ihrer sinnbetörenden Frucht nicht die menschlichen Sorgen in die Winde. Viel stärker als ihr bin ich! Denn (260) wenn es meinen Wein nicht gibt, sind die Mähler bei Tisch freudlos; wenn es meinen Wein nicht gibt, sind die Tänze ohne Zauber. Wenn du kannst, Eulenäugige, dann trinke die Frucht deines Ölbaums! Meine wunderbare Gabe, der Weinstock, hat dein Gewächs besiegt, weil mit deinem fetten Öl sich die Athleten freudlos (265) ihren Körper salben, und ein Mann, wenn er schlimm leidet und vom gleichzeitigen Tod der Gattin und der Tochter getroffen wird, oder voll Schmerz ist, wenn seine Eltern gestorben sind, die Mutter oder der Vater: Wenn er aber vom süßen Wein kostet, dann wird er den verhassten Auswuchs des sich mehrenden Kummers abschütteln können.

(270) Ampelos! Auch nach deinem Tod erfreust du das Herz des Bakchos! Mit allen meinen Gliedern werde ich deinen Trank mischen. Und rund herum neigen sich alle Bäume herab, nicken mit ihrem Wipfel, krümmen ähnlich einem Bittsuchenden ihren gebeugten Nacken, und hoch oben beugt die alte Dattelpalme ihre langen Blätter. (275) Um den Apfelbaum breitest du deine Füße aus, und um den Feigenbaum legst du deine Hände, um dich an ihn zu drücken. Sie stützen deine Frucht wie Mägde ihre Herrin, wenn du mit dem gewundenen Schwung deiner zitternden Blätter über die Schulter der Dienerinnen hinausreichst. Und die Brisen streichen über die reizenden, (280) verschiedenfarbigen Blätter der nahe wachsenden ertragreichen Trauben wie über dein Gesicht, wenn du schlummerst, kühlend, mit schonenden Luftzügen, wie wenn eine Dienerin wie gewohnt den zarten Fächer schwenkt und ihrem König einen kühlen Luftzug verschafft. (285) Und wenn du zur Mittagszeit die Bedrohung durch Phaethon erträgst, dann erreicht der etesische Wind vorauseilend deine Traube und stillt den Durst weckenden Stern der feurigen Maire, dann, wenn dich der Lauf der Sommerhore wärmt und den reifenden Tau im Dampf des Sirius aufheizt.“ (290) Voll Stolz sprach er und verwarf die früheren Sorgen, weil er nun als Heilmittel für den Jungen die wohlriechende Frucht hatte.

Der Rede des Dionysos wurde in der frühen Nonnos-Forschung gelegentlich der Echtheitscharakter aberkannt. ${ }^{76}$ Tatsächlich gewährt die Rede jedoch einen Einblick in

75 Die Umkehrung eines literarischen Motivs findet sich in Nonn. D. 12,249f.: Die Aufnahme des Ampelos in seiner neuen Erscheinungsform als Getränk untergräbt das in der Bukolik geläufige Thema der Unerreichbarkeit der Liebe; zum Motiv vgl. Konstan (1994) 168f.; zur Bukolik in der AmpelosEpisode siehe Kap. 5.3.

76 Vgl. Vian (1995a) 204 (555) Anm. 19. 
die narrative Konzeption der Ampelos-Episode, da Nonnos die zentralen Ereignisse darin Revue passieren und seine Figur Dionysos über den Höhe- und Endpunkt seiner Erzählung, Ampelos' Verwandlung in einen Weinstock, reflektieren lässt.

Von den drei in einem Atemzug genannten Protagonisten, dem Wein, Ampelos und Dionysos (Nonn. D. 12,207) wird der Fokus zunächst auf Ampelos gelegt, der in mehreren direkten Anreden als der Erfinder der soeben in die Welt gekommenen

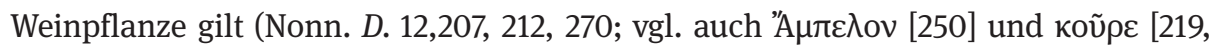
226]). ${ }^{77}$ Ein letztes Mal wird die Rubrik Todesart für Ampelos aufgeboten, allerdings mit der Betonung seines ewigen Lebens, das er durch die Verwandlung in einen Weinstock erlangt. ${ }^{78}$ Die Synkrisis des Ampelos mit mythischen Figuren, die das Todesschicksal ereilt, stellt ein weiteres Glanzstück nonnianischer Rhetorik dar (Nonn. D. 12,212-231), indem durch sechsfache Verneinung dem Tod auch auf lexikalisch-stilistischer Ebene eine Absage erteilt und Ampelos' Auferstehung effektvoll in Szene gesetzt wird. ${ }^{79}$

Noch ausführlicher als in der Atropos-Rede entwickelt der Dichter aus dem Enkomion auf Ampelos Schritt für Schritt ein Enkomion auf die Weinrebe. ${ }^{80}$ Dabei folgt er wiederum nicht strikt den Vorgaben der Rhetorenschule, sondern verteilt ausgewählte Kompositionselemente innerhalb der Rede. Was Aussehen und Eigenschaften betrifft, werden abermals die rote Farbe und der Glanz der Trauben (Nonn. D. 12,225-228) sowie der Duft der Pflanze hervorgekehrt (231-233). Breiten Raum nimmt auch die Schilderung des Pflegeaufwands und des Wachstums ein; die bei Libanios als Nachteil gewerteten Eigenschaften - der Bedarf einer Stütze für das Wachstum sowie die Reifezeit im Hochsommer (Nonn. D. 12,272-284; 12,285-289) - dienen bei Nonnos zur Hervorhebung besonderer Qualität. Die Nützlichkeit der neuen Pflanze besteht ferner in ihrer Fähigkeit, den Menschen feste wie flüssige Nahrung zu bieten (Nonn. D. 12,211, 270 f.), sowie in ihrer Verwendung als Trankspende bei Opferhandlungen (229-231),

77 Vgl. auch die zahlreichen weiteren direkten Anreden des Dionysos an Ampelos: oú (Nonn. D.

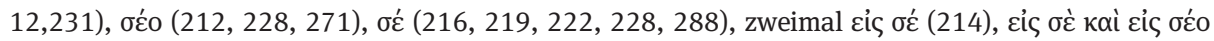

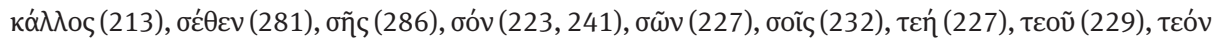

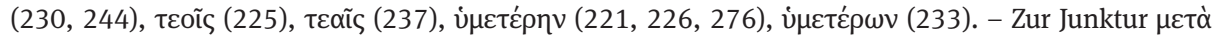

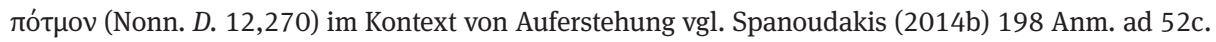
78 Für Hades und Lethe in Nonn. D. 12,219f. und an anderen Stellen bei Nonnos siehe Spanoudakis (2014b) 288f. Anm. ad 165c.

79 Vgl. auch die Negationen in Nonn. D. 12,209-211, 224, 228, 229, 237-239, 254, 255, 257 und $260 \mathrm{f}$.

80 Die neue Pflanze und der Wein werden mittels einer Vielzahl weitgehend synonymer Wörter be-

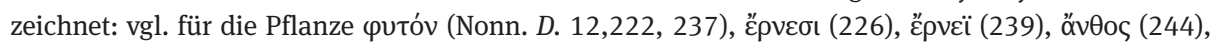

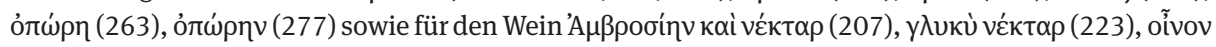

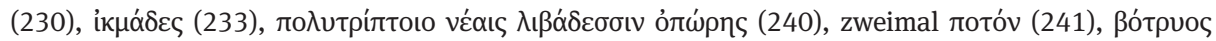

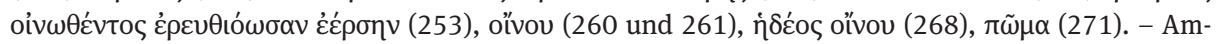
pelos erhält ein zweites Porträt, jedoch in seiner neuen Gestalt; waren es in Nonn. D. 10,175 - 192 noch die Röte der Wangen, die Haare und die Gliedmaßen, so sind nun die Teile des Weinstocks Gegenstand

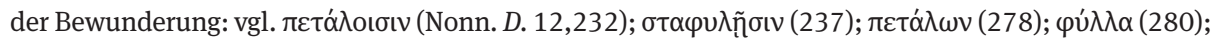

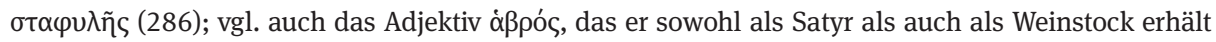
(Nonn. D. 10,179; 12,280). 
favorisiertes Getränk beim Gelage (259-261) und Trostmittel für die menschliche Psyche (263-269). Nonnos spielt bewusst mit Ampelos' ambiger Natur, die zwischen sterblichem Satyrn, unsterblicher Pflanze und wohlschmeckendem Wein changiert, ${ }^{81}$ ebenso wie er mit dem Lob der neuen Pflanze auch das Bekenntnis zu Dionysos' Göttlichkeit verbindet. ${ }^{82}$ In einer Art Ethopoiie - Was würde der Gott sagen, wenn er zum ersten Mal von seinem Wein kostete? - lässt der Dichter Dionysos die Geschehnisse selbst kommentieren. ${ }^{83}$ Die Rede, die in der Formulierung seiner eigenen Genealogie - zweimal bezeichnet Dionysos seinen Vater Zeus als Initiator der Metamorphose (Nonn. D. 12,207, 222f.) - und im Lob auf seinen eigenen göttlichen Status

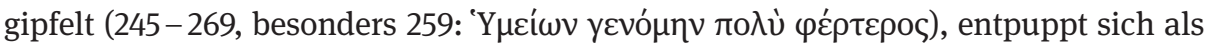
Selbst-Enkomion auf Dionysos.

Obwohl der Alternativmythos zur Entstehung des neuen Getränks am Ende der Ampelos-Episode als Gegenentwurf zum Mythos um Ampelos gedacht ist und keinerlei mythische Verbindung zu diesem aufweist, knüpft Nonnos hinsichtlich der Verarbeitung des Genus Enkomion dennoch an das Vorhergehende an (Nonn. D. 12,292397). ${ }^{84}$ Zusätzliche Informationen $\mathrm{zu}$ Aussehen und Wachstum werden in der Ekphrasis des unkultivierten Weingartens geliefert, wenn neben dem Garten als solchem (Nonn. D. 12,294-303) die Trauben in ihren unterschiedlichen Farben und Reifestadien akribisch beschrieben werden (304-313) und zudem das Wuchs- und Kletterverhalten des Weines erörtert wird (314-318). Mit der Schlange als Erfinderin des Weinpressens (Nonn. D. 12,319-328), der Erfindung der Keltergrube und des Winzermessers durch Dionysos sowie der erstmaligen Kultivierung und Nutzbarmachung des Weines (328-336, 337-362) behandelt Nonnos die Frage des yévos ebenso ausführlich wie die Schilderung der Wirkung des Weinkonsums (363-393).

Die Ampelos-Episode bietet das erste umfassende Enkomion auf den Wein und auf Dionysos in den Dionysiaka und schafft somit die Voraussetzungen für Dionysos' bevorstehenden Missionszug. Ihre kompositionelle Bedeutsamkeit findet sich dahingehend bestätigt, dass Rebe und Saft in drei weiteren für das Epos zentralen Passagen dem Dichter Anlass dazu geben, die einmal begonnene enkomiastische Linie weiterzuverfolgen. Die erste Stelle findet sich im Indien-Zug, wo nicht Dionysos oder einer seiner Gefolgsleute, sondern ein gegnerischer Inder eine Preisrede auf das einzigartige Getränk hält (Nonn. D. 14,419-437), in welcher der angenehme Duft

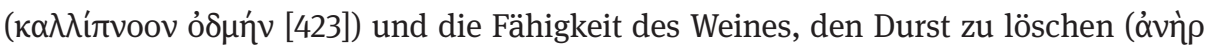

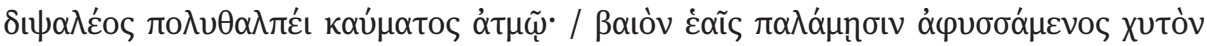

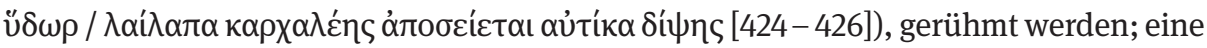
abschließende Synkrisis mit dem Honig und dem göttlichen Nektar streicht die besondere Eigenschaft des Weines hervor, auch bei exzessivem Konsum keinerlei Sättigungsgefühl hervorzurufen (427-429, 430 - 437).

81 Vgl. Vian (1995a) (204) 555.

82 Zur Frage von Dionysos’ menschlichem und göttlichem Status vgl. auch Bowersock (1994).

83 Zur Ethopoiie bei Nonnos vgl. Agosti (2005).

84 Zum Alternativmythos siehe auch S. 141-145 und 231-233. 
Der Duft des Weines, die Konkurrenz zum Nektar und die Synkrisis mit einem anderen Agrarprodukt, der Milch, sind auch Gegenstand der Rede, die Dionysos an den Hirten Brongos in Nonn. D. 17,74-80 richtet. Zu den bisherigen Argumenten für den Weingenuss kommt die sorgenlösende Wirkung hinzu (ö $\lambda \eta \varsigma$ ö $\mu \pi \alpha \nu \mu \alpha \mu \varepsilon \rho i ́ \mu v \eta \varsigma$ [Nonn. D. 17,74]). Diese wiederum ist besonders in der dritten Szene von Belang, in der Methe, die Gattin des von Dionysos im Weingenuss unterwiesenen Königs Staphylos, das Getränk als Trostmittel gegen den Schmerz um ihren früh verstorbenen Mann preist (Nonn. D. 19,23-41), ein Sujet, das bereits aus der Dionysos-Rede im 12. Buch bekannt ist, wo sich ein anonymer óvń $\rho$ ebenfalls mit Wein über den Verlust von Familienangehörigen hinwegtröstet (12,265-269). Ferner wird der Weingenuss Staphylos schon zu Lebzeiten näher gebracht, wenn er und seine Familie den Duft des bislang unbekannten Getränks bewundern und den positiven Begleiterscheinungen wie Musik, Tanz, Trunkenheit und bakchischer Ekstase frönen (Nonn. D. 18,100 - 153). Die Beschreibung der Trunkenheit, kenntlich an Marons und Botrys' roten Wangen, erinnert an das einleitende Porträt des Ampelos, dessen unvergleichliche Schönheit sich ebenfalls in der zarten Röte seines Teints äußert (Nonn. D. 12,179, 188). Die erste Beschreibung des Weines in der Ampelos-Episode ist somit richtungsweisend für die übrigen Bücher der Dionysiaka, da sie die einmal skizzierten enkomiastischen Konturen wiederholt und verstärkt.

Das rhetorische Bild wird durch weitere Textstellen vervollständigt, in denen Nonnos ähnliche Argumente $\mathrm{zu}$ einem Psogos komponiert. Dass Enkomion und Psogos in der rhetorischen Tradition eng beieinanderliegen, wird am Beispiel des Psogos des Libanios auf den Wein ersichtlich (Lib. Prog. Invec. 8 Gibson). ${ }^{85}$ Auch Nonnos setzt in den Dionysiaka die schon aus dem Enkomion auf den Wein geläufige Argumentationsführung mehrmals im Sinne eines Psogos ein, etwa in der negativen Bewertung des sonst positiv besetzten Weines durch Dionysos' Gegenspieler Orontes, der vor der toxischen Wirkung warnt (Nonn. D. 17,172-175), ${ }^{86}$ von Hera, welche die unabsehbaren Folgen des Weingenusses für die Olympier zu bedenken gibt (31,243250), ${ }^{87}$ und von Pentheus, der die negativen Folgen des exzessiven Weinkonsums hervorhebt (45,82-94). ${ }^{88}$ Zahlreiche Motive, die bereits aus den Enkomien in der Ampelos-Episode bekannt sind, finden sich in der Schmährede des Pentheus wieder Dionysos als Erfinder des Weines, die Folgen des Weintrinkens und Dionysos' göttliche Abstammung, die Pentheus in einer rhetorischen Beweisführung anzuzweifeln sucht, indem er in einer Synkrisis zwischen Dionysos und Zeus Ersterem aufgrund des Fehlens der charakteristischen Blitze die Göttlichkeit abspricht (Nonn. D. 46,10 - 51; oủ

85 Zur Verwendung von Enkomion und Psogos in den Dionysiaka sowie zu Nonnos' Vorliebe für Kontraste siehe Miguélez Cavero (2010).

86 Zur Rede des Orontes vgl. Gerlaud (1994) 139-142.

87 Zur Rede Heras vgl. Vian (1997) 56-59.

88 Zur Rede des Pentheus vgl. Simon (2004) 60 - 63, 202 f. - Zu den Pentheus-Büchern vgl. D’Ippolito (1964) 165-177; Tissoni (1998); Hernández de la Fuente (2001b); Aringer (2002); Hernández de la Fuente (2008) $151-165$. 


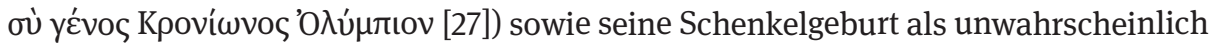

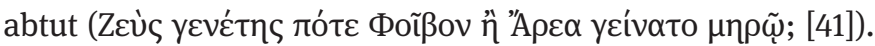

Nonnos kopiert das Enkomion-Schema, wie es in den Progymnasmata zu finden ist, nicht einfach, sondern selektiert, adaptiert und arrangiert es im Hinblick auf die angestrebten narrativen Ziele seines Epos. Die einzelnen enkomiastischen Rubriken werden zu signifikanten Gestaltungsmitteln, um das Lob auf Ampelos und die neue Pflanze im Enkomion auf Dionysos zu kumulieren. Mit dem Sieg über seine Gegner siegt auch das Enkomion über den Psogos, sodass der Weingott, legitimiert durch die tief greifenden kulturellen Veränderungen, die sein Attribut mit sich bringt, zum neuen König unter den Göttern wird. ${ }^{89}$ Gleichzeitig mit der Etablierung von Dionysos als Gott definiert Nonnos auch sein eigenes poetisches Programm: So wie die Weinrebe lediglich in Symbiose mit anderen Pflanzen gedeihen kann, öffnet der Dichter einen bunten Fächer literarischer Traditionen und gestaltet unter Subsumierung sämtlicher literarischer Genera sein eigenes dionysisches Epos. ${ }^{90}$

\subsection{Die Ekphrasis}

Auch das Stilprinzip des Deskriptiven - Ekphrasen von Orten, Städten, Figuren, (Kampf-)Handlungen, Fauna, Flora und unbeseelten Gegenständen - begegnet allenthalben in den Dionysiaka und wurde zunächst als den epischen Erzählfluss beeinträchtigend gewertet; ${ }^{91}$ die geradezu exzessive Häufung von Beschreibungen spreche gegen jegliche episch-narrative Linie, wie sie von den homerischen Epen her geläufig ist. Beobachtungen sowohl in den Literaturwissenschaften als auch in der Nonnos-Forschung der letzten Jahrzehnte haben diese Bewertung jedoch relativiert und entkräftet.

Die Definition von Ekphrasis in den modernen Kunst- und Literaturwissenschaften ist mitunter äußerst heterogen. Einer sehr eng gefassten Begriffsklärung zufolge, die gemeinhin von kunstgeschichtlicher Seite vertreten wird, handelt es sich dabei um die literarische Beschreibung eines Kunstwerks, ${ }^{92}$ eine literarische Gattung, für die es auch nicht an antiken Beispielen fehlt: Wohlbekannt sind die Beschreibungen von 80 Statuen in den Konstantinopolitaner Zeuxippos-Bädern des Christodoros von Koptos (6. Jh. n. Chr.), ${ }^{93}$ die Beschreibung der Hagia Sophia des Paulos Silentiarios (6. Jh. n. Chr.) ${ }^{94}$, die Tabula mundi des Johannes von Gaza (6.

89 Vgl. Miguélez Cavero (2010) 24: „The poem becomes a means of persuading the audience of the

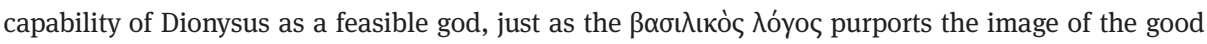
emperor.“

90 Vgl. Shorrock (2013) $211 \mathrm{f}$.

91 Vgl. Bury (1889) Bd. 1, 318: „[...] and that he falls into prolix digressive descriptions.“

92 Vgl. Webb (2009) 28-37.

93 Vgl. Tissoni (2000); Jeffreys (2006a) 127 -131; Bär (2012); Whitby (2016).

94 Vgl. Friedländer (1912); Dihle (1989) 613. 
Jh. n. Chr.), ${ }^{95}$ die Ekphrasen des Prokopios von Gaza ${ }^{96}$ oder die umfassende Abhandlung über die Bautätigkeit Justinians des Prokopios von Kaisareia (6. Jh. n. Chr.). ${ }^{97}$ Die Bildbeschreibung existierte im 6. Jh. n. Chr. als eigene literarische Gattung und wurde in der Folge in der byzantinischen Literatur weiter gepflegt, ${ }^{98}$ gleichwohl sind Kunstbeschreibungen schon für die Frühzeit der griechischen Literatur bekannt: Die erste Ekphrasis findet sich bei Homer, der mit der Schildbeschreibung im 18. Gesang der Ilias die Ekphrasis als typisches erzählerisches Element in der epischen Dichtung verankert. Die zum Musterstück gewordene Schildbeschreibung wird von Vergil im 8. Buch der Äneis aufgegriffen, auch Quintus Smyrnaeus bietet in seinen Posthomerika drei umfangreichere Ekphrasen - auf die Schilde des Achill und Eurypylos sowie auf den Bogen des Philoktet. ${ }^{99}$ Auch Nonnos stellt sich in die Nachfolge Homers und bedient sich der literarischen Beschreibung von Gegenständen und Kunstwerken, indem er, dem Vorbild des Schildes des Achill folgend, eine Beschreibung des Dionysos-Schildes einfügt (Nonn. D. 25,380-572); ${ }^{100}$ weitere bedeutende Ekphrasen sind die Beschreibung der Halskette der Harmonia $(5,135-189)^{101}$ und die Präsentation der prophetischen Tafeln der Harmonia (41,338-360). ${ }^{102}$

Die Definition der Ekphrasis als literarische Beschreibung einer bildlichen Darstellung ist sehr jung und lässt sich erst seit der zweiten Hälfte des 19. Jhs. nachweisen. Hingegen bieten antike Begriffserklärungen ein anderes, umfassenderes Bild, wonach jegliche Art von bildhafter Darstellung als Ekphrasis klassifiziert wurde. Das Ziel ist stets, die Erzählung mit besonderer Intensität und Ausdruckskraft zu versehen und den Leser vollständig in das Geschehen des Textes einzubinden: ${ }^{103}$ „Ekphrasis was a technique used to make the audience feel involved in the subject matter, to make them feel as if they were at the scene of a crime, or that they themselves witnessed the achievements for which an emperor is being praised.“104

95 Vgl. Friedländer (1912); Gigli Piccardi (2011); Lauritzen (2011).

96 Siehe Procop. Gaz. Op. VIII (= Descr. 1); Op. IX (= Descr. 2); vgl. Kennedy (1994) 255.

97 Vgl. Haury u. Wirth (2001).

98 Vgl. Maguire (1974); Maguire (1981) 22 f.; Ciccolella (2000) LV, LXf.; Cameron Averil (2010) 134f. Zur Bedeutung der Ekphrasis in der Literatur der Spätantike siehe Charlet (1997) 551-553; Gigli Piccardi (2003) 8-10; Cupane (2006). - Vgl. auch Elsner (2002a) 2-4 und Kalinka u. Schönberger (2004) über Philostrat und seine Imagines.

99 Vgl. Baumbach (2007); Maciver (2012) 13, 39-66.

100 Vgl. Miguélez Cavero (2008) 298-300.

101 Vgl. Collart (1930) 81; Haidacher (1949) 114.

102 Vgl. auch Aphrodite am Webstuhl (Nonn. D. 24,242 - 260), in der ihr Webstück beschrieben wird; siehe dazu Villarrubia (1994 - 1995); Kröll (2011). - Ein gesteigertes Interesse an Visuellem ist auch für Nonnos' Paraphrase des Johannes-Evangeliums zu beobachten, in der die Ekphrasis ebenfalls eine strukturbildende Funktion erfüllt, vgl. Franchi (2013) 168-181.

103 Vgl. Clark (1957) 201-203; Rosenberg (2007); Webb (2009) 5-10, 51-55.

104 Webb (2009) 10. 
Antike Definitionen sind in den Progymnasmata zu finden: ${ }^{105}$ Die Gegenstände einer Ekphrasis - Personen $(\pi \rho o ́ \sigma \omega \pi \alpha)$, Objekte und Tatsachen (

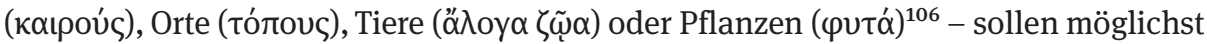

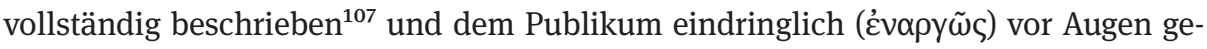
führt werden. ${ }^{108}$ Diese breite Definition von Ekphrasis erlaubt es, in den Dionysiaka zahllose deskriptive Passagen festzumachen: So wird etwa dem ägyptischen Nil genauso eine Ekphrasis gewidmet wie den indischen Flüssen Indos und Hydaspes oder dem lydischen Paktolos. Derartige Passagen sind nur auf den ersten Blick von der narrativen Linie abgekoppelt. Wenn der Dichter einem Ort, einer Figur oder einem Ereignis durch ausführliche Beschreibung besondere Aufmerksamkeit widmet, dann tut er dies stets im Hinblick auf seine narrative Linie, so etwa in der Ekphrasis der Stadt Berytos/Beirut (Nonn. D. 41,14-50), in der er die Bedeutsamkeit Beroes, der Tochter Aphrodites und Namensgeberin der Stadt, für den Weg des Dionysos in den Olymp akzentuiert; Ähnliches gilt für Tyros, dessen beeindruckende Architektur der Gott persönlich besichtigt (Nonn. D. 40,298-365). Mit derartigen Ortsbeschreibungen spannt der Dichter seinen epischen Kosmos auf und konstruiert den Aktionsraum für seine Figuren. ${ }^{109}$ Ekphrasen müssen bei Nonnos stets in enger Verbindung zur Erzählung gesehen werden, mit der sie über gemeinsames Wortmaterial, Themen oder Motive in Relation stehen. ${ }^{110}$ Sie unterbrechen den Verlauf der Handlung nicht, sondern bieten eine Orientierungs- und Interpretationshilfe, ${ }^{111}$ indem Inhalte der Ekphrasis früher oder später in der Erzählung aufgegriffen, einzelne Aspekte der Handlung gespiegelt sowie deren Ausgang kommentiert, antizipiert ${ }^{112}$ und nachbereitet werden. Ekphrasis kann die Grenzen der bloßen Beschreibung sprengen, die Funktion der Haupterzählung übernehmen oder auch Alternativlösungen zur eigentlichen Erzählung bieten, indem sie diese wertet und interpretiert oder aber vom engen erzählerischen Rahmen der Haupthandlung wegführt und den Blick auf einen er-

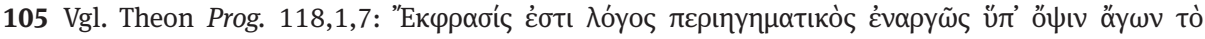

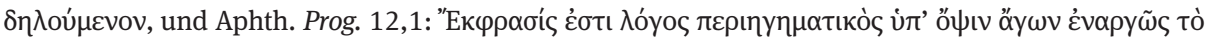
$\delta \eta \lambda$ oú $\mu \varepsilon v o v$.

106 Vgl. Aphth. Prog. 12,1; außerdem Hermog. Prog. 10,1; Nicol. Prog. 68,12-17 Felten; siehe auch Downey (1959) 922.

107 Es soll z. B. eine Person von Kopf bis Fuß und eine Aktion von Beginn bis Ende präsentiert werden, vgl. Kennedy (1994) 206; Webb (2009) 54, $61 \mathrm{f}$.

108 Vgl. Clark (1957) 201 - 203; Kennedy (1983) 65; Kennedy (1994) 206; Ueding (1994) Bd. 2, 549 553; Elsner (1995) 24-28; Graf (1995) 145 -147; Desbordes (1996) 134; DNP 3, 942 -950; Elsner (2002a) 1f.; Lausberg (2008) 544; Miguélez Cavero (2008) 283 - 288; Zeitlin (2013) 17.

109 Vgl. auch die Städte im Katalog der indischen Truppen (Nonn. D. 26) und die Paläste des Emathion (3,124-183) und des Staphylos (18,62 - 92); zum Palast des Staphylos vgl. Elliger (1975) 421-423 und Faber (2004).

110 Zu den vielfältigen Funktionen von Ekphrasis vgl. Graf (1995) 150-152; Bartsch u. Elsner (2007) I. 111 Vgl. Elsner (2002a) 5.

112 Diese Art von Ekphrasis bezeichnet Antonios Rengakos als „proleptische Ekphrasis“, vgl. Rengakos (2006) 12. 
weiterten Kosmos lenkt. ${ }^{113}$ Der Dichter kann einen Sprung vom speziellen Fall des unmittelbaren Geschehens zum Universalen, Allgemeingültigen unternehmen, wobei er die Verbindung zur übergeordneten Handlung beispielsweise durch die Verbindung des beschriebenen Objektes mit einer Figur der Handlung oder durch die Einsetzung einer Beobachter-Figur herstellen kann und so eine Brücke zum Leser schlägt. ${ }^{114}$ Insbesondere ab dem Hellenismus bildet die Komplexität der intra- und intertextuellen Bezüge, die die Autoren durch die Ekphrasis herstellen, ein breites Spektrum von literarischen Ausdrucks-, Variations- und Innovationsmöglichkeiten, ${ }^{115}$ eine Tradition, an die Nonnos anknüpft.

In Zusammenhang mit der viel diskutierten Kompositionsfrage verweist Thierry Duc darauf, dass gerade der Ekphrasis eine wesentliche Rolle zukomme: „L'ekphrasis a donc très nettement fonction de charnière entre la narration épique et la trame généalogique qui provient de l'enkomion. “116 Ekphrastische Passagen erfüllen, so Duc, häufig die Funktion von sog. Konnektoren, erzählerischen Elementen, die zwei aufeinanderfolgende kontrastierende Szenen durch ein gemeinsames Motiv oder Thema miteinander verbinden. ${ }^{117}$ Dabei kommt es neben der Schaffung eines Netzes an Bezugslinien zwischen verschiedenen Büchern des Epos auch auf die sprachliche Umsetzung visueller Eindrücke an: Dem Rezipienten werden Örtlichkeiten, Figuren und Ereignisse regelrecht vor Augen geführt. Beides, die verstärkt angewandte Visualisierung und das Geflecht von thematischen Bezügen und Verweisen, schafft eine Komposition, die weniger linear als flächig und in die Breite verläuft, sodass der Leser zum regelrechten Zuschauer eines Spektakels, gleichsam nicht nur zum Augen-, sondern auch zum Ohrenzeugen des epischen Geschehens wird. ${ }^{118}$

Die Analyse der wichtigsten visualisierenden Passagen in der Ampelos-Episode, ihrer kompositorischen Rolle und ihrer künstlerisch-ästhetischen Ansprüche, kann Einiges zu einem besseren Verständnis der Formensprache der Dionysiaka und des spätantiken Epos insgesamt beitragen. In der folgenden Darstellung der narrativen Funktionen der Ekphrasen in den Büchern 10-12 gilt es, das Genus Ekphrasis als wesentliches poetisches Mittel zur Strukturierung des Erzählablaufes herauszuarbeiten.

Mit der Szene der am Ufer des Paktolos spielenden Satyrn in Nonn. D. 10,139-174 setzt Nonnos eine Ekphrasis an den Beginn der Episode, bereitet durch die Darstellung

113 Vgl. Elsner (2002a) 6 - 8. Zur kosmischen Dimension von Ekphrasen vgl. Hannah (2002).

114 Vgl. Fowler D. (1991) 27. Zum Lesepublikum als Zuschauer bei der Ekphrasis vgl. Elsner (2007); Goldhill (2007) 2, $17 \mathrm{f}$.

115 Vgl. Elsner (2002a) 4: „It is striking that in genres like epic, where many examples of ekphraseis survive, the intertextual patterns of reference become extraordinarily complex [...]. At the same time, there is a tendency to push the limits of what is possible in ekphrasis even further - into other topoi within narratives [...].“ - Goldhill (2007) 2: „In the Hellenistic period, the viewer aims for a clever, pointed, intellectualized revelation of the sediments of meaning.“

116 Duc (1990) 188.

117 Vgl. Duc (1990) 189.

118 Vgl. Schmiel (1998) 398. 
des Ortes, der Figuren und der Handlung auf die bevorstehende Geschichte vor und bietet eine erste Skizze von Inhalt und Ziel der Episode. ${ }^{119}$ Nonnos macht hier den Auftakt zu kommenden Ereignissen im Erzählverlauf und bietet dem Publikum eine erste Orientierungshilfe für die Geschehnisse um Dionysos' Lieblingssatyrn, indem er das ausgelassene Spiel des Weingottes und seiner Begleiter nicht als bloße Staffage vorführt, sondern aufs Engste mit der Erzählung um den jungen Satyrn verwebt. Nicht nur das Wettschwimmen zwischen Dionysos und Ampelos in den Fluten des Paktolos wird vorweggenommen, sondern auch die Genese des Weinstocks und die Ausstattung des neuen Gottes mit seinem Hauptattribut. Das Wasser, in dem die Satyrn sich tummeln, verknüpft die vorhergehende Szene um den Sturz der vor dem Wahnsinn des Athamas ins Meer flüchtenden Ino mit der folgenden Geschichte um die Entstehung des Weines. Zusätzlich zur indirekten Vorwegnahme des erst später in der AmpelosEpisode auftauchenden Weines durch die Betonung des Elements Wasser zeigt das Spiel der Satyrn im Paktolos Dionysos' traditionelle Kultbegleiter erstmals in Aktion; beide zusammen, Wein und Satyrn, werden am Schluss des 12. Buches die Ausstattung des neuen Gottes komplettieren, die detailreiche Beschreibung der Szenerie ist Prolog für die folgende Erzählung.

Ebenso auf das Ziel der Episode arbeitet der Dichter mit dem Porträt des Ampelos hin (Nonn. D. 10,175-192): ${ }^{120}$ Mit der Bezeichnung „Spross der Eroten“ für Ampelos (Nonn. D. 10,178), der rötlichen Farbe seines Gesichts (179), den sich ringelnden Haarlocken (182) sowie dem mehrfach angewandten Glanzmotiv, das den Satyrn in die

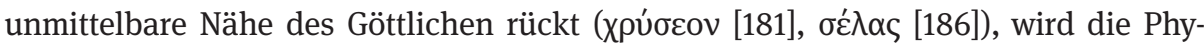
siognomie der Weinpflanze vorweggenommen. Der allenthalben als Folie für die Erzählung dienende Wein bildet auch in der Vorstellung der vier Jahreszeiten am Ende des 11. Buches den narrativen Kern der Ekphrasis.

\section{Das Porträt der Horen}

Nach der Kalamos-Karpos-Erzählung kann Eros Dionysos’ Schmerz ob des Verlustes seines Lieblingssatyrn nur wenig lindern; trotz seiner ausführlichen Parabel über das Schicksal von Kalamos und Karpos und seiner Autorität als erster Gott des dionysischen Zeitalters vermag der Liebesgott allein Dionysos keinen Trost zu verschaffen (Nonn. D. 11,482-485). Um Ampelos' Bestimmung zu verdeutlichen, verlässt der Dichter mitten in Vers 11,485 seine Erzählung, vollzieht einen abrupten Schwenk auf die göttliche Ebene und beschreibt in aller Ausführlichkeit der Reihe nach vom Winter bis zum Herbst die vier Göttinnen der Jahreszeiten. ${ }^{121}$ Schon aus den einleitenden

119 Zur Eingangsszene der Ampelos-Episode vgl. Kap. 2 und Kröll (2013b).

120 Siehe dazu Kap. 3.

121 Der unerwartete Bruch in der Komposition veranlasste die frühe Nonnos-Forschung dazu, diese Stelle als sekundären Einschub in die Dionysiaka zu sehen, vgl. Scheindler (1880) 35-37; Braune (1935) 12 -16. D’Ippolito (1964) 259 - 261 sieht Ov. met. 2,27 - 30 als Vorbild für Nonnos’ Porträt der 
Versen wird klar, dass die Ekphrasis in den Handlungszusammenhang eingebettet ist (Nonn. D. 11,485-521): ${ }^{122}$

'A $\tau \alpha \theta \dot{\varepsilon} \circ \delta_{\delta} \delta \dot{\varepsilon}$

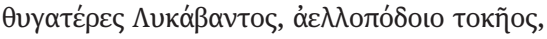

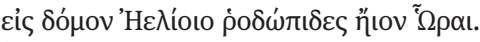

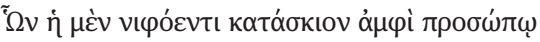

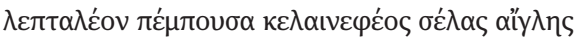

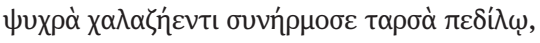

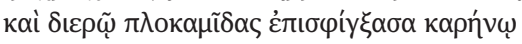

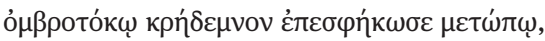

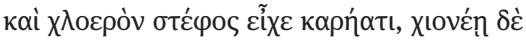

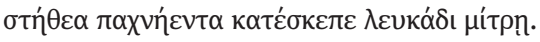

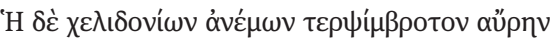

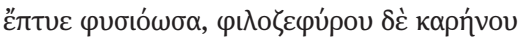

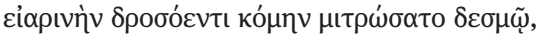

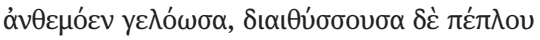

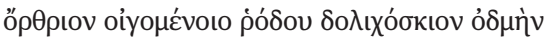

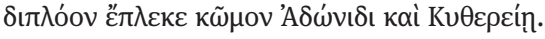

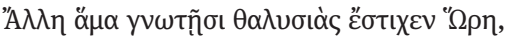

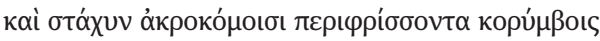

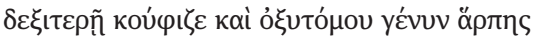

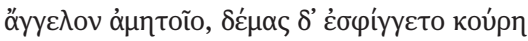

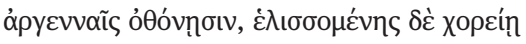

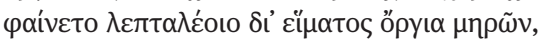

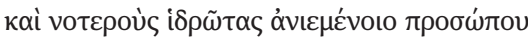

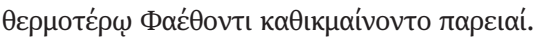

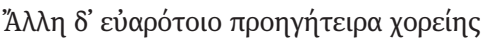

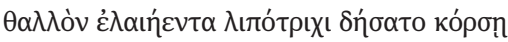

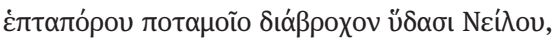

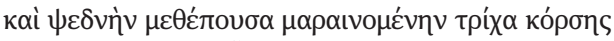

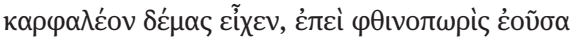

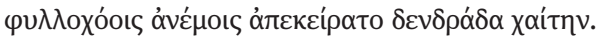

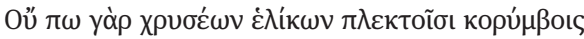

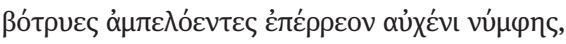

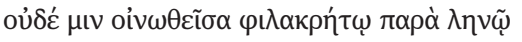

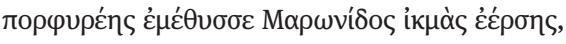

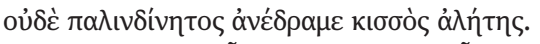

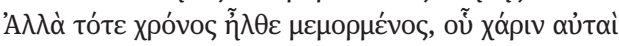

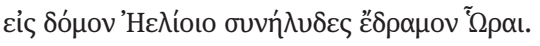

(485) Aber die Töchter des unsteten Jahres, des windschnellen Vaters, die rosengesichtigen Horen gingen zum Haus des Helios. Die eine von ihnen entsandte um das schneeige Antlitz einen schattigen, zarten, schwarzwolkigen Strahlenglanz. (490) Sie hatte an ihre kalten Füße Sandalen

Horen; Ziel sei es für Nonnos, durch die vorgenommenen dichterischen Modifikationen den lateinischen Dichter zu überbieten; zur Bezugnahme der Ekphrasen des Nonnos auf die Haupterzähllinie der Dionysiaka siehe auch Lovatt (2013) 195 - 197; für einen Forschungsüberblick über die Ekphrasis der Horen in der neueren Literatur siehe Nizzola (2012) $68 \mathrm{f}$.

122 Zur Ekphrasis der Horen siehe auch String (1966) 75 f.; Kröll (2013a). 
aus Hagelschloßen gebunden, ihre Locken auf dem nassen Haupt zusammengefasst und über ihrer regenbringenden Stirn einen Schleier angeheftet. Einen grünen Kranz hatte sie auf ihrem Haupt, und ihre froststarrende Brust bedeckte sie mit einem schneeig weißen Tuch.

(495) Die Nächste verströmte blasend den Hauch der Schwalben tragenden Winde, der den Menschen Freude bereitet. Und auf ihrem westwindliebenden Haupt hatte sie ihr Frühlingshaar mit einem Band aus Tau bekränzt. Blütenhell lachte sie, schüttelte aus ihrem Peplos den langschattigen Duft einer sich frühmorgens öffnenden Rose, (500) und fügte sie zu einem Doppellied auf Adonis und Kythereia.

Eine andere schritt zusammen mit ihren Schwestern, die Hore der Ernte, und hielt mit der Rechten eine von Körnern sich wiegende Ähre mit Grannen an der Spitze hoch und eine Sichel, scharf an der Schneide, als Botin der Mahd. Und der Körper des Mädchens war umhüllt (505) von hellleuchtenden Kleidern, und wenn sie sich im Tanz drehte, schien durch das feine Gewand das Geheimnis ihrer Schenkel. Und die feuchten Schweißperlen auf ihrem hoch erhobenen Gesicht wärmten ihre von der Sommersonne durchglühten Wangen.

Eine andere, die Führerin auf dem gut gepflügten Acker und im Reigentanz, (510) hatte den jungen Spross eines Olivenbaumes um ihre kahle Schläfe gewunden, der von den Wassern des Nils mit seinen sieben Mündungen triefte. Nur spärliche und altersgraue Haare hatte sie auf ihrem Haupt und eine ganz runzlige Gestalt, weil sie der Herbst war und mit ihren die Blätter wirbelnden Winden das Laubhaar der Bäume abgeschoren hatte. (515) Denn noch nicht wallten in goldenen Spiralen und geringelt an den Spitzen Weintrauben herab auf den Hals des Mädchens. Und noch nicht hatte sie sich berauscht an der Kelter, die den ungemischten Wein so liebt, noch hatte sie der purpurne Saft des maronischen Taues trunken gemacht, und noch nicht lief mit seinen Ranken rings um sie herum der wandernde Efeu. (520) Aber da war die durch das Schicksal festgesetzte Zeit schon gekommen, dank derer die Horen gemeinsam eilends ins Haus des Helios liefen.

Nach einer lediglich zweieinhalb Verse umfassenden Überleitung mit dem Gang der Horen zum Helios-Palast (Nonn. D. 11,485 - 487) werden nacheinander die Jahreszeiten porträtiert. Der durch Nässe, Schnee und Frost gekennzeichnete Winter (Nonn. D. 11,488 - 494) wird vom Frühling mit Blumen, Tau und Schwalben abgelöst (495-500), der Sommer mit seinen Werkzeugen, den geernteten Früchten und dem Festtanz (501508) vom Herbst mit kahlem Kopf, der nur provisorisch mit einem Olivenzweig geschmückt ist (509-519). Die Schlussverse zeigen, wie die Horen den Palast betreten (Nonn. D. 11,520 f.), die Szene beendet zugleich das 11. Buch.

Durch die ringkompositorische Rahmung der Ekphrasis und die Abgrenzung von der umgebenden Erzählung gestaltet Nonnos sorgfältig, dazwischen widmet er jeder einzelnen Hore eine bestimmte Anzahl an Versen, dem Winter, Frühling und Sommer annähernd gleich viele, nämlich sieben, sechs und acht, dem Herbst hingegen elf. Allein durch dieses unterschiedliche Verhältnis setzt er Prioritäten. Was die Darstellungsweise der Horen betrifft, hält sich der Dichter an die Konventionen antiker Ikonographie, ${ }^{123}$ indem er den Winter mit Schnee, Hagel, Frost und feuchten Nebelschleiern, den Frühling mit Schwalben, Westwind und Rosen und den Sommer mit Getreideähre, Sichel und Sommerhitze ausstattet. Die detailgenaue Erzählung veranlasste Viktor Stegemann zu der Annahme, dass der Dichter seine Beschreibung auf

$123 \mathrm{Zu}$ den Horen in der spätantiken Kunst siehe Hanfmann (1951) 163-192; Vian (1995) 180; vgl. auch Kap. 7.3. 
der Grundlage einer bildlichen Vorlage angelegt haben müsse. ${ }^{124}$ Die Beliebtheit der Horen in der bildenden Kunst der Spätantike lässt diese Möglichkeit zwar offen, jedoch verfügen die Figuren auch in der antiken Literatur vor Nonnos über einen hohen Beliebtheitsgrad, sodass die Szene wohl in erster Linie das Ergebnis einer langen Tradition darstellt. ${ }^{125}$

Der Dichter offeriert seinem Publikum auch keine realistische Szene im Sinne einer Wiedergabe der momentanen Situation, des Ganges der Horen zum Palast des Helios, dass sie im Begriff sind, sich dorthin aufzumachen, wird lediglich durch den Erzähler in aller Kürze am Ende von Buch 11 angedeutet. Nirgendwo wird die Szene durch Figurenaktion konstituiert, die näher mit der Haupterzählebene in Verbindung steht, stattdessen erfolgt eine emblemartige Präsentation der Horen, die mit ihren typischen Attributen und charakteristischen Handlungen versehen werden. Allein mit den Mitteln der Sprache entwirft Nonnos für jede Jahreszeit ein Sinnbild und versieht es mit einem eindeutig zu identifizierenden Etikett. Es geht dem Dichter nicht darum, eine dramatisch aufgebaute Ereigniskette vom Aufbruch bis zur Ankunft zu knüpfen, also nicht um eine effektive Einbettung der Horen-Szene in den unmittelbaren narrativen Kontext, sondern vielmehr um eine universell gültige Darstellung der vier Jahreszeiten sowie um ihre subtile Einordnung in den Erzählverlauf der AmpelosEpisode. Für jede Hore wird eine individuelle Stimmung erzeugt, die sich an den signifikanten Zügen der jeweiligen Jahreszeit orientiert. ${ }^{126}$ Die jeweils richtige Atmosphäre wird durch die sprachliche Umsetzung von unterschiedlichen Sinneseindrücken geschaffen. Innerhalb der kleinen, in sich geschlossenen narrativen Einheit, die für jede der vier Horen disponiert wird, beschränkt sich Nonnos aber nicht etwa auf eine statische Beschreibung, sondern bietet eine „kinetische Aufladung der Ekphrasis“127 und realisiert Optisches, Akustisches sowie Bewegung. ${ }^{128}$ Während der Schwerpunkt der Beschreibung des Winters auf visuellen Bildern liegt - der äußeren Erscheinung der Hore der kalten Jahreszeit -, kommt es Nonnos beim Frühling auf Bewegung und Akustik an: Der Atem der Hore, der milde Westwind und das Ausschütteln des Peplos werden mit einem gleichsam hörbaren Hymnus auf die Wiedergeburt der Natur verbunden. Die Umsetzung von Bewegung in Sprache steht im Mittelpunkt der Charakterisierung des Sommers, der umhüllt von weißen Kleidern und hocherhobenen Hauptes mit Ähre und Sichel in Händen einherschreitet. Eine Be-

124 Vgl. Stegemann (1930) 129 Anm. 4, 159f.; Haidacher (1949) $120 \mathrm{f}$.

125 Zur literarischen Tradition der Horen siehe Hanfmann (1951) 115-127, 142-159, 210-261.

126 Vgl. Stegemann (1930) 129 Anm. 4.

127 Wandhoff (2003) 55.

128 Vgl. Bartsch u. Elsner (2007) II zur Funktion von Ekphrasis als ein alle Sinne einnehmendes literarisches Mittel: „And even at its most visual - when words group to represent images - it finds itself straying to the evocative resonances of the other senses: sound, smell, taste, and touch.“ - Zur dichterischen Umsetzung von Bewegung und Gestik in den Dionysiaka vgl. Miguélez Cavero (2009a), zur Paraphrase vgl. Franchi (2013) 181 - 190; zu akustischen Effekten in den Dionysiaka vgl. Newbold (2003). 
schleunigung und einen Höhepunkt erfährt diese Dynamik im Erntetanz, den die Hore vollführt.

Nonnos gestaltet die Beschreibung der Horen durch die Einbeziehung aller Sinne besonders anschaulich. Im Zentrum steht die Illusion von Bildern, von Aktion, die durch das Mittel der Sprache kreiert und regelrecht vor Augen geführt wird. Diese vom

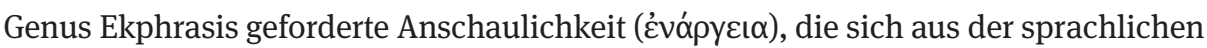
Umsetzung von Bildhaftem ergibt, wird in typisch nonnianischer Weise durch die Erweiterung in den akustischen und gestischen Bereich ergänzt. ${ }^{129}$ Die vielen verschiedenen Eindrücke kumulieren in einer maximalen und alle Sinne ansprechenden Poetik. Die Ekphrasis, von der der unvoreingenommene Rezipient zunächst erwartet, dass sie statisch und rein beschreibend ist, wird zu einem abwechslungsreichen Gebilde, das durch die Einbeziehung aller Sinne eine starke Dramatisierung erhält. Die Beschreibung wird zu einem Mini-Drama, das das Publikum in sämtlichen Bereichen seiner Wahrnehmungsfähigkeit vereinnahmt.

Ein besonderes Ziel verfolgt der Dichter mit seiner Darstellung der Herbsthore: Nonnos gesteht der Protagonistin der bevorstehenden Ereignisse den größten Raum zu, im Gegensatz zu ihren Gefährtinnen, die als Einzelfiguren keine Rolle in der Erzählung spielen. ${ }^{130}$ Die Herbst-Hore mit ihrer besonderen Physiognomie - sie ist ausgetrocknet und hat nur spärliches Haupthaar - entspricht der Jahreszeit, die die Blätter von den Bäumen fegt. ${ }^{131} \mathrm{Im}$ Gegensatz zu ihren Gefährtinnen entbehrt sie fast vollständig jeglichen Beiwerks, eine Ausnahme bildet lediglich ihr kümmerlicher Olivenzweig auf dem Kopf. Ihre üblichen Attribute - Weinranke, Trauben und Efeu fehlen gänzlich. ${ }^{132}$ Der reichen Ausstattung mit Erkennungsmerkmalen bei Winter, Frühling und Sommer wird pointiert die Nicht-Existenz charakteristischer Attribute beim Herbst gegenübergestellt. Mit mehrfachen Negationen wird gleichsam ex negativo all dies aufgezählt, worüber die Hore noch nicht verfügt: Ov้ $\pi \omega$ (Nonn. D. 11,515),

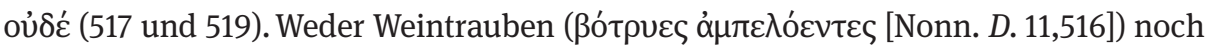

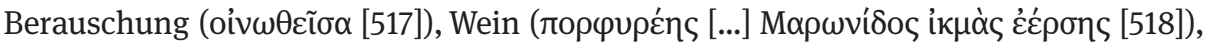
Kelter (

Zwischen den Tod des Ampelos und dessen Wiederauferstehung in Gestalt des Weinstocks schaltet der Dichter eine Szene auf einer übergeordneten, göttlichen Ebene. Der Dichter baut zum einen den Spannungsbogen auf, wenn er nach der

129 Zu évópyeı vgl. Zanker G. (1981); Webb (1997); Lausberg (2008) 399-407.

130 Vgl. Vian (1995) 26.

131 Im Gegensatz zu Nonnos ist bei Ovid der Herbst mit vollem, weißem Haar dargestellt, da die Jahreszeiten mit den Lebensaltern des Menschen parallelisiert werden (Ov. met. 15,211), vgl. Gigli Piccardi (2003) 806.

132 Vgl. Vian (1995) 26f.; Gigli Piccardi (2003) 806. - Nonnos rückt in dieser Götterszene ganz besonders Weinrebe und Wein in den Mittelpunkt. In Nonn. D. 12,21 versieht er nicht nur den Herbst,

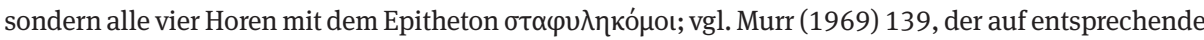
bildliche Darstellungen der Horen mit Weinreben auf dem Kopf verweist.

$133 \mathrm{Zu}$ einer möglichen Rezeption der ungewöhnlichen Darstellung der Herbsthore in der bildenden Kunst siehe Bull (1998) 732 f., 738. 
Trostrede des Eros Ampelos' Metamorphose nicht direkt anschließt, zum anderen begründet er die kommenden Ereignisse gleich doppelt. Nicht nur die Parabel des Eros über Tod und Wiederauferstehung, sondern auch die Ekphrasis der Horen bereitet die Genese des Weines vor. In demselben Ausmaß, in dem Dionysos um seinen verlorenen Gefährten trauert, verlangt die Herbsthore nach den sie charakterisierenden Kennzeichen. Der Reiz der Beschreibung des Herbstes liegt in der Einbeziehung von Zukünftigem: Er verfügt noch nicht über seine typischen Erkennungszeichen, sondern steht erst kurz davor, seine ihm eigenen Attribute verliehen zu bekommen. Erst mit der Einschaltung der Götterebene kann der kosmische Plan in die Tat umgesetzt werden, erst durch den Gang der Horen zum Palast des Helios und die Konsultierung der altehrwürdigen Tafeln der Harmonia ist die Zeit reif für das Kommen des Weinstocks und des daraus gewonnenen Getränks (Nonn. D. 11,520 f.). Die Herbsthore erfüllt eine wesentliche Funktion in der Erzählung um Ampelos, ihre ausführliche Ekphrasis ist somit aus dem narrativen Kontext begründet.

Hinweise auf das Ziel der Erzählung finden sich nicht nur in der Ekphrasis der Herbsthore, sondern auch in den Details der Beschreibung der übrigen drei Horen. Obwohl diese in keiner direkten Verbindung zur Genese des Weines stehen und auch nicht als handelnde Figuren in der Erzählung sichtbar werden, versieht Nonnos sie dennoch mit Komponenten, die auf die bevorstehende Geburt der neuen Pflanze verweisen. Im ersten Vers der Ekphrasis des Winters (Nonn. D. 11,488) knüpft Nonnos

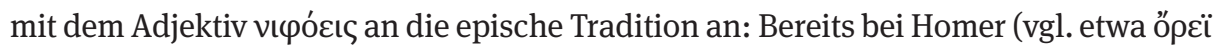
vı

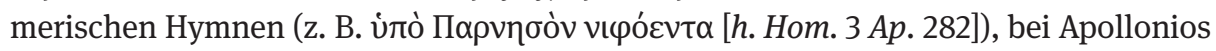

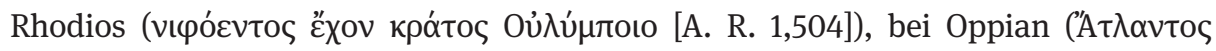

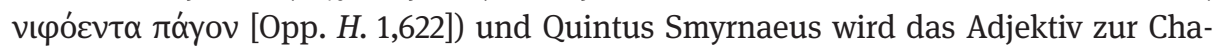

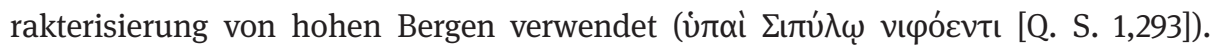
Nonnos setzt das Adjektiv in einen veränderten Kontext und verwandelt den schneebedeckten Berg der epischen Dichtung in die Winterhore mit „schneeigem Antlitz“. ${ }^{134}$ Die mit vıৎócıৎ assoziierten prominenten mythischen Gebirge sind aus

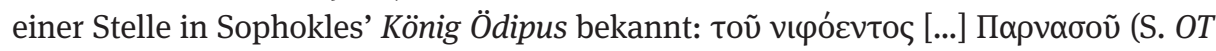
473 - 475). Aus dem narrativen Kontext der Stelle lässt sich eine motivische Parallele zu

134 Ein weiteres Beispiel für Nonnos’ Verwendung epischen Vokabulars in verändertem Kontext ist

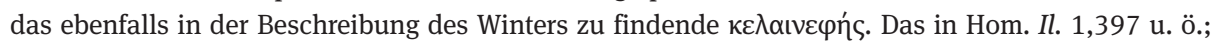
Hom. Od. 9,552 u. ö.; h. Hom. 5 Ven. 220; 2 Cer. 91, 316, 396 u. ö. sowie in Hes. Sc. 53 begegnende Adjektiv ist traditionell ein Beiwort für Zeus, während Nonnos damit die Winterhore charakterisiert. Eine weitere Reminiszenz aus der griechischen Dichtung ist mit diesem Adjektiv verbunden: Der bei

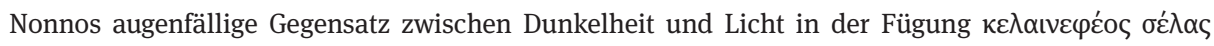

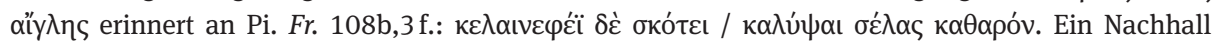
pindarischer Dichtung ist zudem in der folgenden Ekphrasis des Frühlings zu beobachten: Das seltene

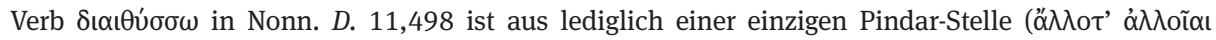

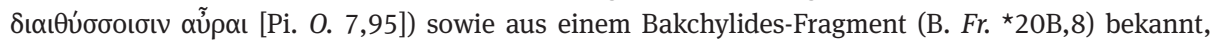
Nonnos macht insgesamt dreimal davon Gebrauch, die anderen Stellen finden sich Nonn. D. 3,406; 20,190; vgl. Stegemann (1930) 132 Anm. 10. 
Nonnos ziehen: Unmittelbar nachdem Teiresias Ödipus selbst als den Mörder des Laios bezeichnet hat, schließt ein Chorlied mit einem effektvollen Bild an; der Chor stellt sich

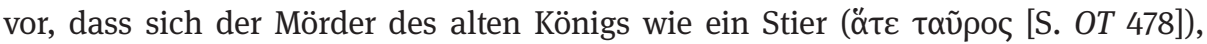
entfernt von jeglicher Zivilisation, in den Wald flüchtet, um seinen Richtern zu entgehen. Ob diese Assoziation der Sophokles-Stelle von Nonnos tatsächlich intendiert ist, ist freilich Spekulation, unbestritten ist, dass dem Motiv des Stieres im Gebirge in der Ampelos-Episode noch eine wesentliche Rolle zukommen wird, wenn der unvermittelt im Gebirge neben Ampelos auftauchende Stier zum Mörder des Satyrn wird. ${ }^{135}$

Auch in der Ekphrasis des Frühlings ist ein Verweis auf die spätere Weinpflanze zu

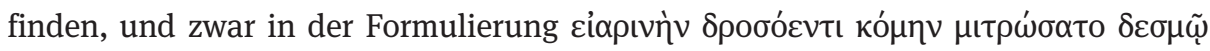
(Nonn. D. 11,497). Die Tatsache, dass die Hore ihr Haupt mit einer Binde aus Tau be-

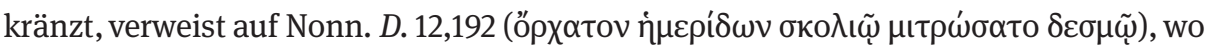
die Krönung des soeben in die Welt gekommenen Weinstocks mit dem ebenfalls erst entstandenen Efeu vollzogen wird. Mit dem Lied der Frühlingshore zu Ehren des Adonis und der Kythereia/Aphrodite, einem beliebten Sujet der hellenistischen Dichtung, ${ }^{136}$ wird zudem auf den Tod des Ampelos verwiesen: Das tragische Schicksal des Adonis, des Geliebten der Aphrodite, der vor seiner Zeit stirbt, steht parallel zum Los des Ampelos, genauso wie die Liebe einer Gottheit zu einem sterblichen Wesen nur vorübergehend mit Trauer und Schmerz ob dessen gewaltsamen Tod durch ein wildes Tier verbunden ist, da die Entstehung einer neuen Blume der Gottheit Trost spendet. Thematisiert wird im lediglich angedeuteten Mythos der periodische Wechsel zwischen Werden und Vergehen, der auch den Kern der Ampelos-Episode ausmacht.

Die Beschreibung des Sommers bringt als zusätzlichen Vorverweis auf Dionysos' Rolle als anerkannter olympischer Gott die őpyı $\mu \eta \rho \tilde{\omega} v$, „das Geheimnis der Schenkel“ ins Spiel (Nonn. D. 11,506). ${ }^{137}$ Der Dichter appliziert hiermit einen wichtigen Terminus, der bereits ab Nonn. D. 3,263 Sinnbild für die mystische Natur des bakchischen Kultes ist, insbesondere in Nonn. D. 9,287, wo im Rahmen eines kultischen Festes für Dionysos die Bakchen unter Zuhilfenahme von Heilkräutern Ino von ihrem Wahnsinn heilen.

Anstatt mit der Ekphrasis der Jahreszeiten eine rein bildhafte Darstellung zu bieten, setzt der Dichter auf eine allumfassende Wirkung und macht die Horen durch die Mittel seiner Sprache gewissermaßen sicht-, hör- und erlebbar. Die Ekphrasis

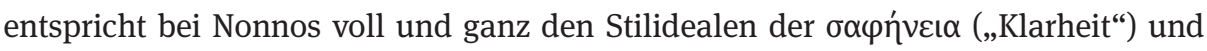

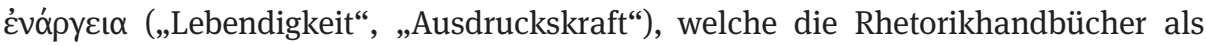
besondere Merkmale dieser Gattung nennen, ${ }^{138}$ und ist Lesehilfe für diejenigen, die sich im bunten Geflecht einzelner Episoden der Dionysiaka zurechtfinden wollen. Sie spiegelt gleichzeitig frühere Ereignisse im Epos sowie den Ausgang der AmpelosEpisode. Die Horen erinnern an dieser Stelle sowohl an den Willen des Zeus als auch

135 Das Gebirge ist traditioneller Ort göttlicher Epiphanie, vgl. Buxton (1994) $91 \mathrm{f}$.; Accorinti (2003) 1. 136 Vgl. etwa Bion I,16f., 27 f., 37 f., 63 f., 69 f., 85 f. Beckby.

137 Vgl. Vian (1988a) 407 (451); Gigli Piccardi (2003) 560.

138 Vgl. Hermog. Prog. 10,6. 
an Dionysos selbst, mit dem sie schon in dessen Kleinkind- und Jugendalter in Verbindung standen. Ebenso wie diese die Vorgeschichte zur Ampelos-Episode ins Spiel bringen, verweisen sie durch die Funktion als Vegetationsgöttinnen auch auf deren Ausgang. Sie sind Symbol für das zyklische Werden und Vergehen, das im Schicksal des Ampelos gespiegelt wird. Die epische Inszenierung der Herbsthore ist zugleich eine Anspielung auf die bevorstehende Wende innerhalb der Erzählung, an Ampelos' Tod wird sich seine Wiedergeburt anschließen. Mit ihrem Auftritt werden die Attribute des Weingottes - Weintrauben, Kelter, Wein und Efeu - vorweggenommen. Mit der Darstellung der Horen, Personifikationen von Zeit und periodischer Wiederkehr, ordnet Nonnos die neue Pflanze in die Kosmologie der Dionysiaka ein und weist so der Ampelos-Episode einen präzise abgegrenzten Platz innerhalb der Geschichte um Dionysos' Aufstieg in den Olymp zu.

\section{Die Tafeln der Harmonia}

Bei den vier prophetischen Tafeln an den Wänden des Helios-Palastes handelt es sich um eine Bildbeschreibung, eine Ekphrasis im engeren Sinn, die für das Verständnis und die Komposition der Ampelos-Episode von essentieller Bedeutung ist. ${ }^{139}$ Nonnos verlässt am Ende des 11. Buches den Schauplatz um Dionysos und den Trost spendenden Eros und hebt die Darstellung auf eine übergeordnete Erzählebene, indem er neue Figuren, die Personifikationen der vier Jahreszeiten, präsentiert, welche hinsichtlich der Komposition eine maßgebende Rolle einnehmen. Der Dichter gestaltet den Übergang von der Dionysos-Handlung zu den Horen besonders auffällig, abrupt und mitten im Vers (Nonn. D. 11,485) an der Stelle der bukolischen Dihärese unterbricht er Dionysos' Trauer und leitet zur neuen Szene über.

Tatsächlich setzt Nonnos die Szene mit den Horen jedoch nicht beliebig an diese Stelle, sondern fügt sie in den narrativen Kontext ein: In den ersten 40 Versen des 12. Buches wird von der Ankunft der Horen der vier Jahreszeiten bei Helios und der Horen der zwölf Stunden berichtet (Nonn. D. 12,1-20), ${ }^{140}$ woraufhin die Herbsthore ihre Bitte an den Sonnengott persönlich richtet, sie doch darüber in Kenntnis zu setzen, wann sie die ihr zustehenden Attribute bekommen werde (23-28). Helios antwortet mit einer Handbewegung in Richtung der Tafeln an der Wand (29-35) sowie mit dem Hinweis, dass sie auf der dritten ihr eigenes Schicksal wiederfinden werde (36-40). Nachdem die Herbsthore an die Tafeln herangetreten ist, kann die eigentliche Ekphrasis be-

139 Zur Szene im Palast des Helios siehe Stegemann (1930) 122-172 und 197-199 (mit einem Überblick über die Tafeln); Zuenelli (2013). - Die Tafeln der Harmonia werden auch in der Paraphrase genannt, vgl. Nonn. P. 5,154; 7,160.

140 Nonnos verbindet an dieser Stelle unterschiedliche Traditionen um die Horen, indem er die vier Jahreszeiten-Horen und die zwölf Monats- oder Stundenhoren nebeneinander setzt; für eine ähnliche Konfusion der Horen der Jahreszeiten, Monate und Stunden siehe Q. S. 1,48 - 51 und 2,593 - 595 sowie Jo. Gaz. 1,314-360 und 2,259-313, vgl. Vian (1995) 184. 
ginnen. Die ersten beiden Tafeln sind sowohl kompositorisch als auch inhaltlich aufs Engste miteinander verbunden (Tafel 1: Nonn. D. 12,41-55; Tafel 2: Nonn. D. 12,55-63):

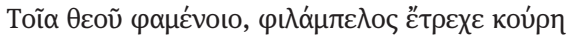

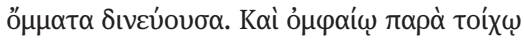

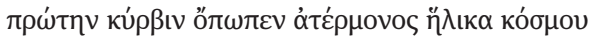

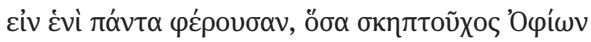

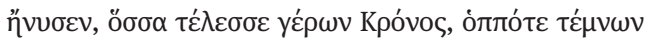

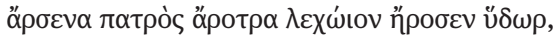

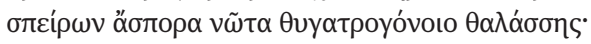

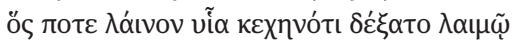

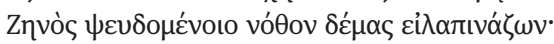

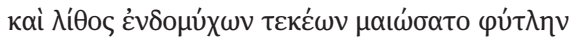

50

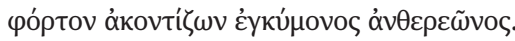

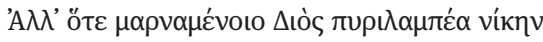

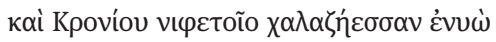

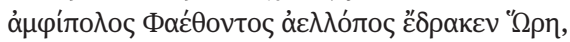

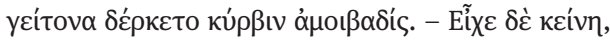

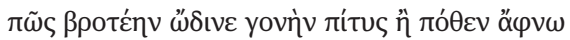

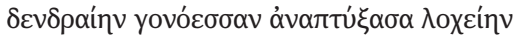

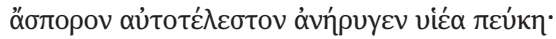

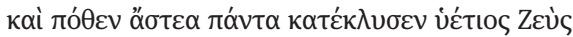

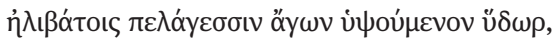

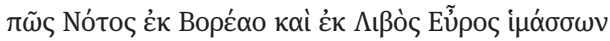

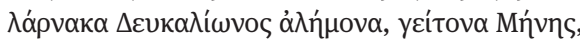

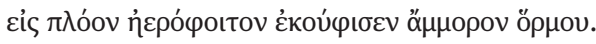

Nachdem der Gott dies gesagt hatte, lief das Mädchen, die Freundin der Rebe, los und ließ ihre Augen umherschweifen. Und an der prophetischen Wand erblickte sie die erste Tafel, so alt wie der endlose Kosmos, in Einem all das erfassend, was der Herrscher Ophion (45) geschaffen und was der alte Kronos vollendet hatte, als er die männliche Pflugschar seines Vaters abschnitt und in das gebärende Wasser einpflügte, indem er den unfruchtbaren Rücken des tochtergebärenden Meeres besamte. Der nahm später einmal im klaffenden Schlund einen Stein statt seines Sohnes auf und verspeiste den untergeschobenen Leib des vorgeblichen Zeus. (50) Und der Stein brachte die Brut der tief drinnen verborgenen Kinder wieder zur Welt, indem er die Last aus dem schwangeren Rachen herausschleuderte.

Aber nachdem die Dienerin des Phaethon, die windfüßige Hore, den feurig lodernden Sieg des kämpfenden Zeus und den eisigen Kampf des schneeigen Kronos betrachtet hatte, (55) wechselte sie den Blick zur Tafel daneben. Und diese hatte zum Inhalt, wie die Fichte einen menschlichen Spross gebar, wie die Föhre plötzlich als Sprössling eine Baumgeburt entband und einen nicht gezeugten, von selbst vollendeten Sohn hervorbrachte; und wie der Regenbringer Zeus alle Städte überschwemmte, (60) indem er aus den tiefen Meeren das Wasser hoch empor lenkte; und auch wie der Notos aus dem Norden und aus Libyen der Euros Deukalions umhertreibende Barke durchpeitschten, in unmittelbarer Nachbarschaft zu Mene, und wie sie ihre Bahn hoch hinauf in die Luft lenkten weit entfernt von jeglichem Ankerplatz.

Die Tatsache, dass es sich um eine Bildbeschreibung handelt, wird vom Erzähler an mehreren Punkten eindeutig markiert, indem er die Fiktion der Erzählung unterbricht. Das Publikum bekommt die Gelegenheit, die Herbsthore zu beobachten, wie sie in Echtzeit die Bildtafeln abschreitet, bei jeder einzelnen kurz verweilt und sie betrachtet 
(Nonn. D. 12,41- 43 und 54f.). Nonnos bringt hier eine besondere Art von Fokalisation zur Anwendung: Nach Helios' demonstrativer Geste in Richtung der Tafeln blickt der Leser gleichsam auf die Bilder einer Ausstellung und besucht diese zusammen mit der Hore. ${ }^{141}$ Indem Nonnos aus dem Blickwinkel der Herbsthore erzählt, bietet er keine objektive und neutrale Bildbeschreibung, sondern gibt eine konsequente Richtung vor, um so eine Auslegung der Götterszene um Helios und die Horen für den Rezipienten zu bestimmen. ${ }^{142}$ Die nachdrückliche Einbeziehung des Publikums in die Erzählung hebt außerdem die Bedeutung, die die Palastszene für die Ampelos-Episode im Kleinen und das Epos im Großen hat. Der evolutionäre Prozess, dem sich Dionysos unterziehen muss, um eine von allen anerkannte vollwertige Gottheit zu werden, ist Inhalt der beiden ersten Tafeln: Der auf der ersten Tafel präsentierte Sukzessionsmythos setzt mit Ophion ein, welcher in der orphischen Religion solange als Urherrscher des Kosmos gilt, bis er von seinem Sohn Kronos entmachtet wird, der seinerseits wieder von Zeus abgelöst wird. ${ }^{143}$ Mit der ersten Tafel verbindet Nonnos zwei Traditionen, und zwar die Orphik mit der klassischen, bereits seit Hesiod gängigen mythischen Herrschaftsfolge Uranos/Kronos/Zeus (Hes. Th. 154-210, 453-506). An den Urmythos von den ersten Göttergenerationen schließt auf der zweiten Tafel die Darstellung der Genese des ersten Menschengeschlechts an, das der Fichte entsprungen war und durch die von Zeus gesandte Sintflut vernichtet wurde. ${ }^{144}$

Nonnos liefert mit dieser Ekphrasis zugleich eine Kosmo- und eine Theogonie und schafft so die kosmische Legitimation der Geschehnisse um Dionysos und Ampelos. Die Machtübernahme und -ausübung durch Zeus bereitet den Boden für seinen Sohn, den Weingott. Dionysos wird in die Götterwelt eingeordnet, führt die Regentschaft seines Vaters fort und sichert sich damit seine universale Machtposition. Mehrfach zieht Nonnos in dieser Ekphrasis Verbindungslinien zu seiner Erzählung: Ähnlich wie die Geschwister seines Vaters erwartet Dionysos eine doppelte Geburt, aus seiner Mutter und aus seinem Vater. So wie der Stein die olympischen Götter aus dem Bauch des Kronos wieder ans Licht bringt (Tafel 1), entschlüpft Dionysos dem Schenkel des Zeus; auch das Motiv der Spontangeburt findet sich wieder, wenn Dionysos förmlich aus dem Schenkel seines Vaters platzt und sogleich von den Horen empfangen wird (Nonn. D. 9,11-15); ähnlich entspringen auf der zweiten Tafel die ersten Menschen „plötzlich“ der Fichte (’’ $\varphi v \omega[12,56])$. Zeus’ Sieg über Kronos in der traditionellen Mythologie reflektiert Zeus' Sieg über Typhon im 1. und 2. Buch der Dionysiaka sowie

141 Vgl. Stegemann (1930) 160: „Wir begleiten die Hore längs der Wände des Heliospalastes. Hier kommt Bewegung in das Momentane des Phaethonbildes [...].“

142 Zur metapoetischen Funktion der Herbsthore als Bindeglied zwischen Text und Leser siehe Fincher (2016). - Auch in der Literatur wird auf die besondere Funktion der Ekphrasis als bewusster Lenkung der Rezeption verwiesen, vgl. Fowler D. (1991) 29: „[...] a literary description necessarily inscribes a point of view more strongly than a plastic one [...]“, und Knape (2007a) 16: „Aber eigentlich zeigt der Bildmacher mit dem Bild vor, was sich in seinem Bewusstsein an Bildvorstellung befand [...].“ 143 Zu Ophion vgl. Gigli Piccardi (2003) 818 Anm. ad 44.

144 Zur Tradition, in die sich Nonnos hier stellt, vgl. Gigli Piccardi (2003) 819-821 Anm. ad 55-58. 
Dionysos' Triumph über die Inder (Nonn. D. 13-40) und die Giganten (Nonn. D. 48). Zudem nehmen der angedeutete Weltenbrand und die von Zeus geschickte Sintflut die Brände und Überschwemmungen nach dem Tode des Zagreus, des ersten Dionysos, im 6. Buch wieder auf. Die Ekphrasis spiegelt somit wesentliche Aspekte der Erzählung, indem sowohl auf bereits Geschehenes als auch auf Bevorstehendes verwiesen wird. Intratextuelle Bezüge sind nicht nur zu den großen Erzähllinien, sondern auch zur Ampelos-Episode im Kleinen zu finden. Die Geburt der Menschen aus der Fichte auf der zweiten Tafel bietet ein Spiegelbild zur Geburt des Weinstocks aus Ampelos, im ersten Fall entspringt der Mensch aus einer Pflanze, im zweiten wird die umgekehrte Entwicklung geschildert.

Die Hinweise auf das narrative Ziel der Bücher 10-11 werden sich in der Beschreibung der Tafeln drei und vier verdichten. Der Erzähler tritt hier insofern in Erscheinung, als er auch die beiden letzten Tafeln als von der mythischen Tradition ererbte Stücke inszeniert, die das Lesepublikum über die Mittelsperson der Herbsthore der Reihe nach gleichsam leibhaftig und unmittelbar inspizieren darf. Anders als in der Ekphrasis der ersten beiden Tafeln gibt der Dichter hier die Rolle des Erzählers an die Hore ab, indem er sie in sechs bzw. sieben Versen (Nonn. D. 12,64-69, 90 - 96) die bildlich und schriftlich festgehaltenen Prophezeiungen präsentieren lässt. Die Unmittelbarkeit und Nähe der Szene wird durch die beiden direkten Reden der Herbsthore erreicht, welche die eingeschriebenen heiligen Worte verliest (Tafel 3: Nonn. D. 12,64-102):

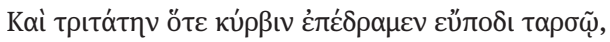

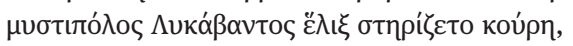

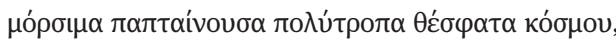

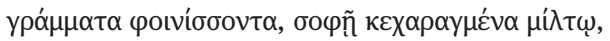

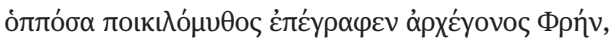

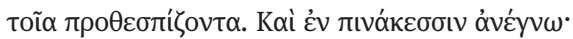

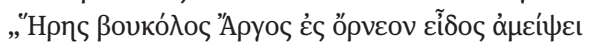

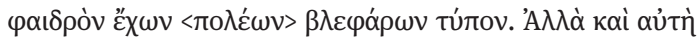

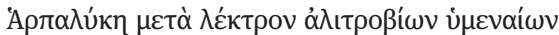

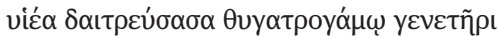

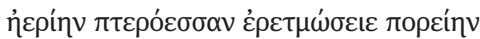

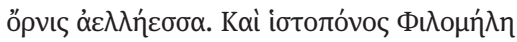

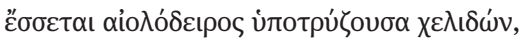

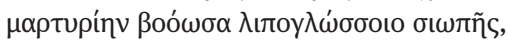

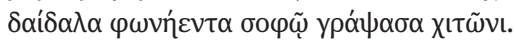

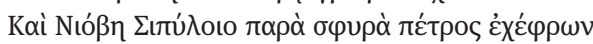

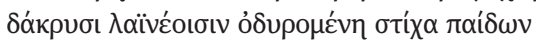

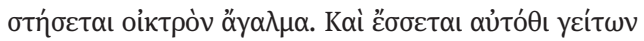

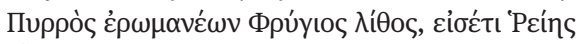

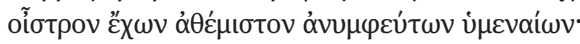

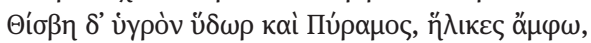

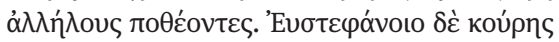

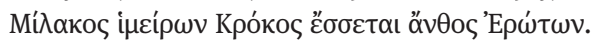




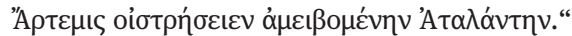

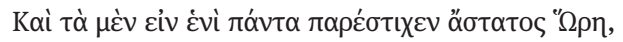

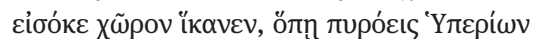

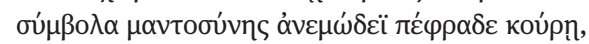

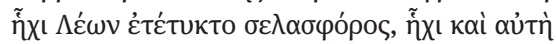

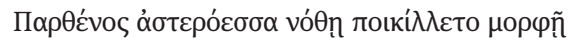

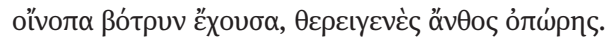

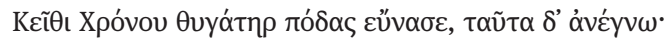

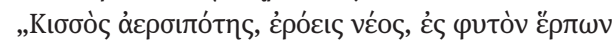

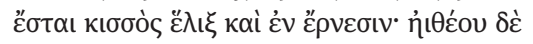

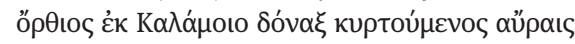

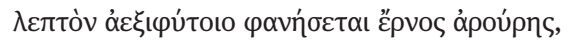

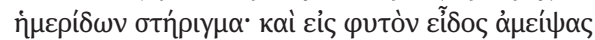

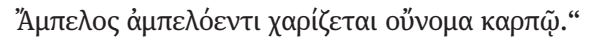

Und nachdem die Mystendienerin des Jahres mit schön gesetztem Schritt, sich windendem, zur dritten Tafel gegangen war, (65) blieb das Mädchen stehen. Sie blickte staunend auf die schicksalshaften, vielgewandten Orakel für die Welt, in purpurroten Buchstaben, auf weißlichem Ocker gut sichtbar eingeschrieben; diese hatte mit bunten Geschichten der erstentstandene Denk-Sinn als Prophezeiung folgendermaßen aufgeschrieben. Und auf den Tafeln las sie: (70) „Der Hirte der Hera, Argos, wird seine Gestalt in einen Vogel verwandeln, mit dem leuchtenden Abbild vieler Augen. Aber auch sie, Harpalyke, wird nach dem Bett der verderbenbringenden Hochzeit ihren Sohn für den Vater, den Bräutigam der Tochter, zerteilen und hoch oben in der Luft mit den Flügeln auf ihrer Bahn (75) als windschneller Vogel rudern. Und die am Webstuhl sich mühende Philomele wird eine zwitschernde Schwalbe mit glänzendem Hals werden, die ihren Zeugenbericht in zungenlosem Schweigen hinausschreit, nachdem sie ein sprechendes Kunstwerk kundig auf einen Chiton geschrieben hat. Und Niobe wird am Fuße des Sipylos als standhafter Felsen (80) mit steinernen Tränen die Riege ihrer Kinder beklagen und als Mitleid erregendes Standbild dastehen. Und dort wird auch ihr Nachbar Pyrrhos sein, der liebestolle phrygische Stein, der immer noch zu Rheia den unerlaubten Liebeswahn nach einer unmöglichen Hochzeit hat; und auch Thisbe als flüssiges Nass und Pyramos, gleichen Alters, (85) sehnen sich nacheinander. Und der sich nach dem schönbekränzten Mädchen Milax sehnt, Krokos, wird eine Blume der Eroten sein. Und nach dem Heiratswahn um die windfüßige Hochzeit und nach den Äpfeln der Paphierin wird Artemis Atalante in die Gestalt einer Löwin verwandeln und wahnsinnig machen.“

(90) All dies schritt die Hore in einem ab, ohne stehen zu bleiben, bis sie an den Ort gelangte, wo der feurige Hyperion die Zeichen der Seherkunst dem windschnellen Mädchen zeigte, wo der glänzende Löwe abgebildet und wo sie selbst, die gestirnte Jungfrau, mit einem falschen Gebilde dargestellt war, (95) die Weintraube haltend, die im Sommer geborene Blüte des Herbstes. Dort verlangsamte die Tochter des Kronos ihren Schritt; und Folgendes las sie: „Kissos, in die Höhe strebend, lieblicher Jüngling, wird auf eine Pflanze kriechen und wird der Efeu sein, sich auch auf den Schösslingen windend. Und aus dem Jüngling Kalamos wird das gerade Schilfrohr entstehen, sich wiegend im Wind, (100) ein zarter Spross des fruchtmehrenden Feldes und eine Stütze für die veredelten Weinreben. Und Ampelos, seine Gestalt in eine Pflanze verwandelt, verleiht der Rebenfrucht seinen Namen.“

Das Abschreiten der Bildtafeln durch die personifizierte Jahreszeit und die Inhalte der Tafeln selbst schaffen eine Ekphrasis auf zwei Ebenen. Der Zweck der Beschreibung der Tafeln sowie des Bittganges der Horen insgesamt besteht in der kosmisch-mythischen Legitimierung der Ampelos-Erzählung und in der Beglaubigung des bevorstehenden Geschehens durch eine Reihe von höheren Instanzen. Die besondere Au- 
torität, die durch Helios und die Horen - den Lenker des Alls und die ihm untergebenen Göttinnen der Zeit - generiert wird, setzt sich in den Informationen der Tafeln fort. Die darauf befindlichen Inschriften sind mit kaiserlicher Purpurfarbe auf hellem

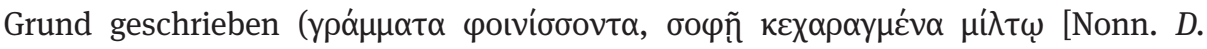

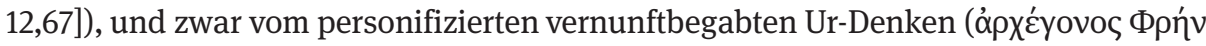
[68]), das im gleichen Atemzug als „reich an Mythen“ und „bunter Mythen kundig“

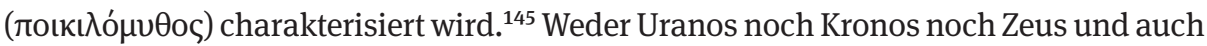
kein anderer oberster Gott sind für diesen kosmischen Plan verantwortlich, sondern ein gottähnliches Abstraktum, das in der Hierarchie über allen Göttern gedacht werden muss und von dem letztlich auch deren Schicksal abhängig ist. Eine Stilisierung der Geschehnisse um Dionysos und Ampelos als schicksalhaft und vorherbestimmt wird zudem durch deren Einordnung in den astrologischen Rahmen erreicht. Die genannten Sternbilder - angedeutet durch oũkoৎ und konkretisiert durch die Nennung von Löwe und Jungfrau - sind ebenso wie Helios und die Horen der Dimension der Zeitlichkeit zugeordnet. ${ }^{146}$ Die Inszenierung der Geschehnisse als unvermeidlich und von langer Hand geplant hat zum Ziel, das Schicksal des Ampelos als ultimatives mythisches Ereignis zu präsentieren und durch sämtliche mythische Traditionen zu beglaubigen.

Dieses Konzept bildet den Rahmen für den Inhalt der dritten Tafel, der in Form einer längeren Inschrift festgehalten ist. Diese verliest die Herbsthore für die anwe-

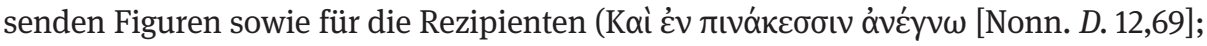
$\tau \alpha \tilde{\tau} \tau \alpha \delta^{\prime} \alpha^{\prime} v \varepsilon^{\prime} \gamma v \omega$ [96]), ${ }^{147}$ wobei der Dichter zunächst nicht erklärt, ob es sich bei den Tafeln um bloße Schrift- oder Bildtafeln oder gar um eine Kombination von beidem

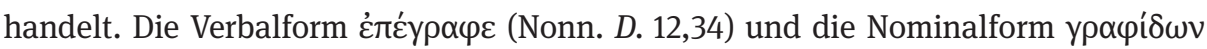
(35) sind diesbezüglich indifferent, da sie sowohl „Schreiben“ als auch „Zeichnen“ meinen können. Auch bei den ersten beiden Tafeln bleibt der Dichter noch indifferent gegenüber dem gewählten Medium und legt sich erst bei der Beschreibung der dritten

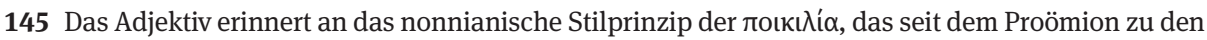
Dionysiaka im 1. Buch verfolgt wird. Wenn der Dichter dem Urprinzip jeglichen Denkens dieselbe Arbeitsweise wie seinem Werk zuschreibt, so macht er aus der kosmischen Autorität der personifizierten Фрฑ́ $v$ eine poetische und erhebt selbst Anspruch auf die Rolle des Archegeten mythischer Dichtung.

146 Stegemann (1930) 161 - 164 ordnet die Darstellungen auf den Tafeln den Tierkreiszeichen zu und gründet darauf seine Theorie der Komposition der Dionysiaka nach dem Muster eines Weltenjahres. 147 An dieser Stelle reflektiert Nonnos die Praxis des mündlichen Vortrags spätantiker Dichtung: Poetische Werke wurden einem gemischt christlichen und heidnischen Publikum präsentiert, das über dieselbe Bildung und denselben sozialen Rang wie der Dichter verfügte. Die charakteristischen sprachlichen und stilistischen Merkmale entfalten erst durch das laute Vortragen ihre volle Wirkkraft. Wie die Herbsthore liest auch Aphrodite in Nonn. D. 41,338-398 die Inschriften auf den Tafeln der Harmonia vor, vgl. Agosti (2010). - Zur Bedeutung von Schriftlichkeit im spätantiken Christentum vgl. Lane Fox (1994). 
fest, bei welcher es sich um eine Kombination von Bild und Text handelt. ${ }^{148}$ Die Hore liest zunächst der Reihe nach acht verschiedene Mythen vor, von denen jeder einen ganz bestimmten Themenbereich berührt. ${ }^{149}$ Das erste mythische Sujet, die Metamorphose, wird durch den in einen Pfau verwandelten Argos, die zu Vögeln gewordenen Harpalyke und Philomele, die zu Steinen veränderten Niobe und Pyrrhos sowie die Löwin Atalante bedient, das zweite Thema, das ebenfalls mehreren der angeführten Mythen zugeordnet werden kann, die Liebe, ist vor allem in ihren negativen Ausprägungen dargestellt, da es sich beinahe ausschließlich um unglückliche und tragische Liebesbeziehungen handelt. Durch die Themen Liebe und Metamorphose stellt der Dichter Verbindungslinien zu seinem Ampelos-Mythos her, indem die präsentierten mythischen Figuren einzelne Aspekte ihres Schicksals mit Ampelos teilen.

Nicht nur die Entsprechungen der Themen bereiten auf die weitere Handlung der Ampelos-Episode vor, sondern auch die chronologische Perspektive, die beim Katalog der Mythen eingenommen wird. Die Inschrift präsentiert sich als Prophezeiung, dementsprechend finden sich eine Reihe von Futurformen: á $\mu \varepsilon i ́ \mid \varepsilon$ (Nonn. D. 12,70),

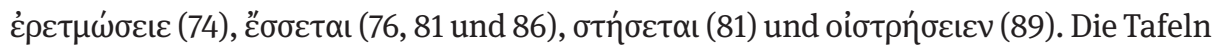
zeigen eine direkte Linie von der Urzeit, symbolisiert durch die Entstehung des Kosmos auf den ersten Tafeln, über die Gegenwart mit den Horen und Helios bis in die Zukunft mit der Genese des Weines. Vergangenheit, Gegenwart und Zukunft treffen in der Ekphrasis der Tafeln aufeinander, welche so eng miteinander verzahnt sind, dass hier jegliche Zeitlichkeit aufgehoben scheint. Die mythische Vorzeit, die gegenwärtigen Tafeln und die nahenden Ereignisse laufen gleichsam synchron ab, ein Nacheinander entsteht lediglich durch das Abschreiten der Tafeln durch die Herbsthore. Dem Publikum wird ein zeitliches Panoptikum geboten, das sich in der Darstellung der Tafeln verdichtet. Die Ampelos-Episode fügt sich homogen in diese mythische Welt ein, ihr Ergebnis, die Entstehung des Weines, ist notwendige Konsequenz der offenbarten Kosmologie.

Die synoptische Schilderung der Tafeln erfüllt sich in der Prophezeiung des Schicksals des Ampelos und seiner Begleiter. Durch Löwe und Jungfrau, die Sternzeichen des Spätsommers und Frühherbsts, werden die Informationen als wahrhaftig stilisiert und gewinnen so an zusätzlicher Glaubwürdigkeit. Eine wesentliche Rolle kommt dabei dem Sternbild der Jungfrau zu, das der Dichter auf besondere Weise

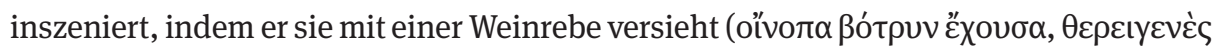

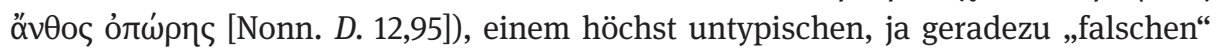

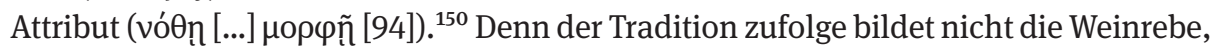
sondern die Getreideähre das charakteristische Attribut dieses Sternzeichens, wie in

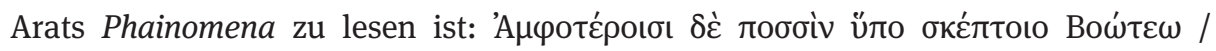

148 Für Stegemann (1930) 168 sind die Tafeln eine Kombination aus bildlicher Darstellung und Inschrift.

149 Vgl. Stegemann (1930) $165 \mathrm{f}$.

150 Zum Sternbild der Jungfrau in den Dionysiaka vgl. Stegemann (1930) $61 \mathrm{f}$.; zum Adjektiv vó $\theta$ os bei Nonnos vgl. Gigli Piccardi (2003) 124f. Anm. ad 31. 


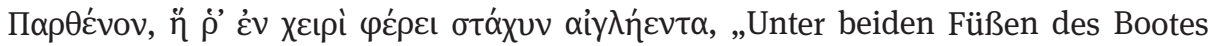
betrachte die Jungfrau, die in der Hand die glänzende Ähre trägt“ (Arat. 96 f.). ${ }^{151}$ Dieses konventionelle Bild der Jungfrau mit Ähre greift Nonnos an anderer Stelle auf, und zwar im 6. Buch der Dionysiaka, wo Demeter Astraios konsultiert, um Genaueres über das Schicksal ihrer Tochter Persephone in Erfahrung zu bringen; dort ordnet Astraios

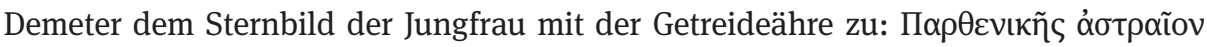

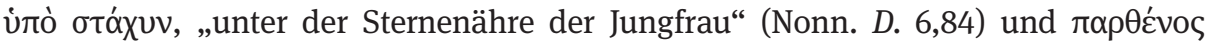

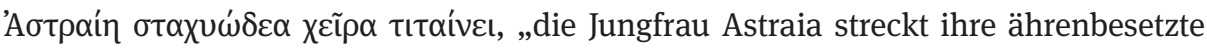

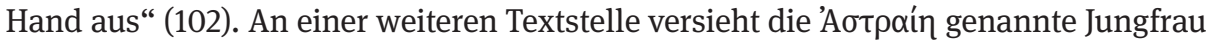
in ihrer Funktion als Amme die kleine Beroe unter anderem mit einem Ährenkranz: кaì

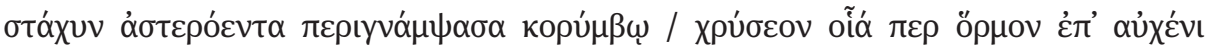

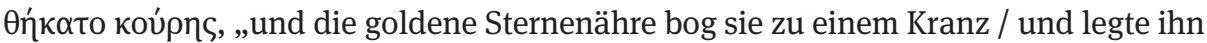
wie eine Kette um den Hals des Mädchens“ (Nonn. D. 41,228f.). Wenn Nonnos zu Beginn des 12. Buches von der literarischen Tradition abweicht, so tut er dies bewusst und im Hinblick auf das narrative Ziel der Horen-Episode. Mit der Zuordnung des Weines zum Sternbild und zur Herbsthore wird der kosmisch-chronologische Rahmen für das folgende Geschehen doppelt festgelegt. Das Kommen des Weines ist durch den Lauf der Sterne unverrückbar vorherbestimmt und gleichsam durch höhere kosmische Instanzen erklärbar. Die Ausstattung der Hore mit ihrem Attribut wird auf der vierten Tafel weiter konkretisiert (Nonn. D. 12,103-117):

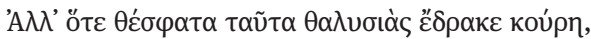

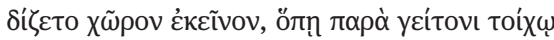

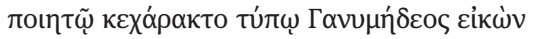

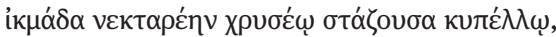

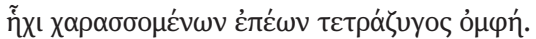

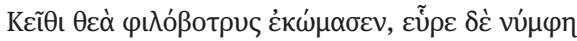

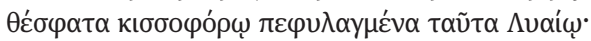

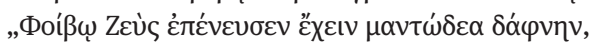

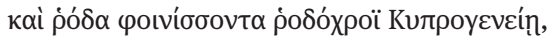

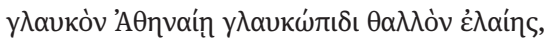

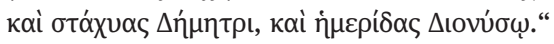

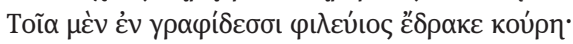

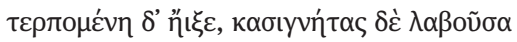

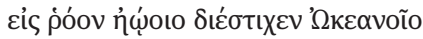

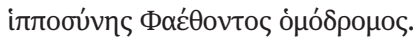

Aber als das Mädchen der Ernte diese Orakel betrachtet hatte, hielt sie auch nach jener Stelle Ausschau, wo an der benachbarten Wand (105) nach dichterischem Abbild das Bildnis des Ganymed gezeichnet war, wie er den Nektarsaft in goldenem Becher ausschenkt; dort war ein vierfacher Spruch von Worten eingezeichnet. Dorthin schwärmte die traubenliebende Göttin, und das Mädchen fand folgende Orakel, die für den efeutragenden Lyaios vorgesehen waren: (110) „Dem Phoibos gestand Zeus den prophetischen Lorbeer als Besitz zu, rote Rosen der rosigen Kyprogeneia, den glänzenden Spross des Ölbaums der glanzäugigen Athene, die Ähren der De-

151 Text: Martin (1998) 6; Übersetzung: Erren (2009) 11. 
meter und die veredelten Reben dem Dionysos.“ Dies sah das Mädchen, die Gefährtin des Euios, auf den Tafeln. (115) Und freudig eilte sie los, ihre Schwestern nahm sie mit und stieg hinein in die Flut des morgendlichen Okeanos auf derselben Bahn wie das Gespann des Phaethon.

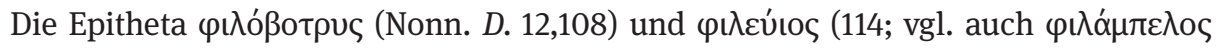
[41]) weisen die Herbsthore als Vertreterin der Weinernte und des Weines aus. Die bildliche Darstellung (عikẃv [Nonn. D. 12,105]) des göttlichen Mundschenks Ganymed wird von einer vier Verse langen Inschrift begleitet, die Synkriseis für Dionysos enthalten (110-113): So wie Zeus Apoll, Aphrodite, Athene und Demeter mit Attributen versehen hat, wird auch Dionysos sein typisches Merkmal sowie den Status eines Gottes verliehen bekommen.

Das narrative Ziel der Ampelos-Episode wird bereits früher angekündigt und wird zu Beginn des 12. Buches vorweggenommen, wenn Helios explizit auf die dritte und die vierte Tafel verweist (Nonn. D. 12,29-40):

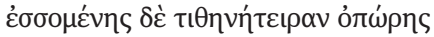

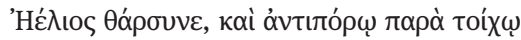

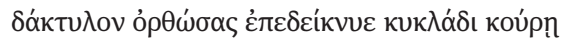

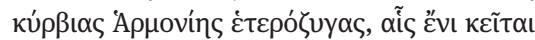

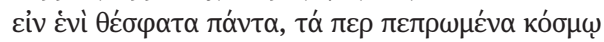

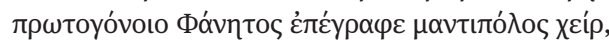

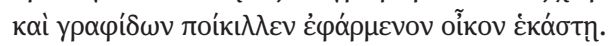

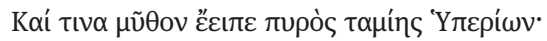

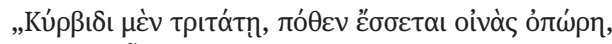

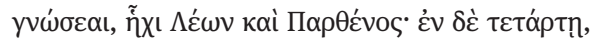

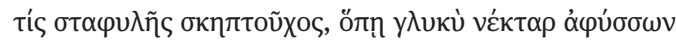

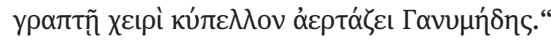

Helios ermutigte die Nährerin der künftigen Frucht, (30) richtete seinen Finger auf die gegenüberliegende Wand und zeigte dem im Jahreskreis wiederkehrenden Mädchen die Tafeln der Harmonia, die eine nach der anderen aufgehängt waren. Auf ihnen waren alle Orakel in einem festgehalten, die für die Welt vorgesehen waren, welche die göttlich inspirierte Hand des Phanes, des zuallererst Geborenen, darauf geschrieben (35) und jeweils mit einem passenden Haus für jedes der Tafelbilder verziert hatte. Und Hyperion, der Hüter des Feuers, hielt eine Rede: „Auf der dritten Tafel wirst du erkennen, woher die Weinrebenfrucht kommen wird, hier bei Löwe und Jungfrau; und auf der vierten, wer über die Traube Herrscher sein wird, da, wo Ganymed den süßen Nektar schöpft (40) und mit der gemalten Rechten den Becher hochhebt.“

Die Worte des Helios bieten eine Zusammenfassung des Ganges der Herbsthore zu den prophetischen Tafeln, wobei die zweifache Beschreibung der dritten und vierten Tafel - in der Rede des Helios und in der Betrachtung der Hore - keine entbehrliche Wiederholung desselben Inhalts darstellt, sondern die Bedeutung der Ekphrasis unterstreicht, die Rezeption des Textes in die vom Dichter gewünschte Richtung lenkt sowie den Zweck hat, „Stimmung und Bedeutung des Folgenden zu exponieren“. ${ }^{152}$ 
Bei der Beschreibung der Tafeln geht es Nonnos zu keinem Zeitpunkt darum, eine Bilderserie mit dem Charakter einer funktionslosen Deskription abzuliefern, ebenso wenig bietet er eine realistische, naturgetreue Beschreibung. Mit den vier Tafeln setzt er unterschiedliche erzählerische Schwerpunkte, indem er Bild und Text unterschiedlich stark gewichtet und stets in Korrelation zueinander setzt. Dem Wort kommt dabei eine so herausragende Rolle zu, dass erst durch die angebrachten Inschriften sowie durch den Akt des Vorlesens durch die Herbsthore die Tafeln ihre vollständige prophetische Wirkung entfalten. Vor allem für die nonnianische Ekphrasis hat der folgende Satz Gültigkeit: „Denn zum einen folgt, dass die Bildbeschreibung nicht des Bildes wegen geschehen ist, sondern der Beschreibung wegen - nicht um das Bild, sondern um das Wort geht es.“153 Nonnos’ Freude am gesprochenen und geschriebenen Wort wird in dieser Ekphrasis besonders deutlich. ${ }^{154}$ Die poetische Auseinandersetzung mit der Inschrift auf den Tafeln, die in der Beschreibung der ,purpurroten

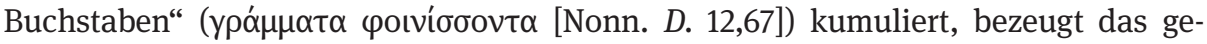
steigerte Interesse der Spätantike an Schriftlichkeit und deren Wirkung. ${ }^{155}$ Die Tafeln der Harmonia erinnern mit ihren göttlichen Orakeln an eine Tendenz, die für viele philosophisch-religiöse Strömungen der Spätantike - für das Christentum ebenso wie etwa für die Orphik oder den Neuplatonismus - relevant ist: die Funktionalisierung von Wort und Schrift als Manifestationen göttlichen Willens und Planens. Ähnlich wie auch in der hellenistischen Dichtung werden die Szenen auf den Tafeln eng an die Geschehnisse der Haupthandlung gekoppelt, ${ }^{156}$ sodass die Ekphrasis zum unentbehrlichen Element für die Komposition wird und dem Dichter zudem die Möglichkeit zur Reflexion über sein eigenes künstlerisches Ausdrucksmedium Schrift sowie über diesbezügliche zeitgenössische Entwicklungen bietet. Sämtliche rhetorische Spielarten finden sich auch in Himerios’ 48. Rede: In das Enkomion auf einen Gouverneur fügt Himerios neben dem Mythos des Philoktet, einer Ekphrasis der Jahreszeiten, einer Synkrisis von Anakreon und der gepriesenen Person auch einen Abschnitt über den Nil und die Nilschwelle sowie einen neuplatonischen Exkurs über die Seele ein, um schließlich auf die Erziehung des Gouverneurs zu sprechen zu kommen. ${ }^{157}$

153 Graf (1995) 153.

154 Vgl. Agosti (2006) 55-59.

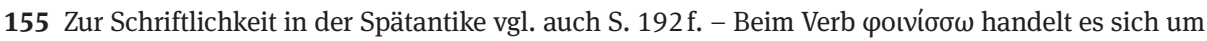

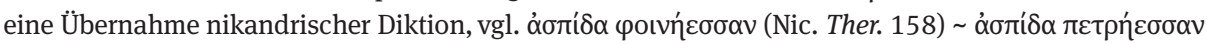

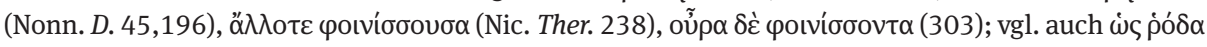

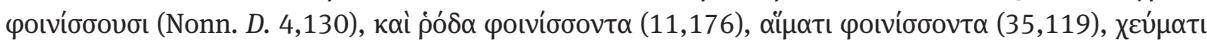

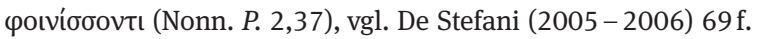

$156 \mathrm{Vgl}$. beispielsweise die Ekphrasis von Iasons Mantel in den Argonautika, die gleichfalls mehr als eine bloße Beschreibung bietet (A. R. 1,721-768).

157 Vgl. Kennedy (1983) 146; Kennedy (1994) 246. - Auch Gregor von Nazianz rezipiert rhetorische Traditionen: In seine Reden 4 und 5, Invektiven auf Kaiser Julian Apostata, integriert er zahlreiche Elemente aus der Progymnasmata-Literatur, so etwa eine Ekphrasis des Ätna oder eine auf die Ankunft Julians in der Unterwelt, vgl. Kennedy (1983) 222. 
Der Ekphrasis bei Nonnos kommt insofern eine essentielle metapoetische Funktion $\mathrm{zu}$, als sie nicht bloß Prolepse und retardierendes Moment ist, sondern als umfassende künstlerisch-kreative Auseinandersetzung mit literarischen Traditionen gelten darf, indem sie die Möglichkeiten des epischen Genres auslotet und Epos und Rhetorik gegeneinander abwägt. 